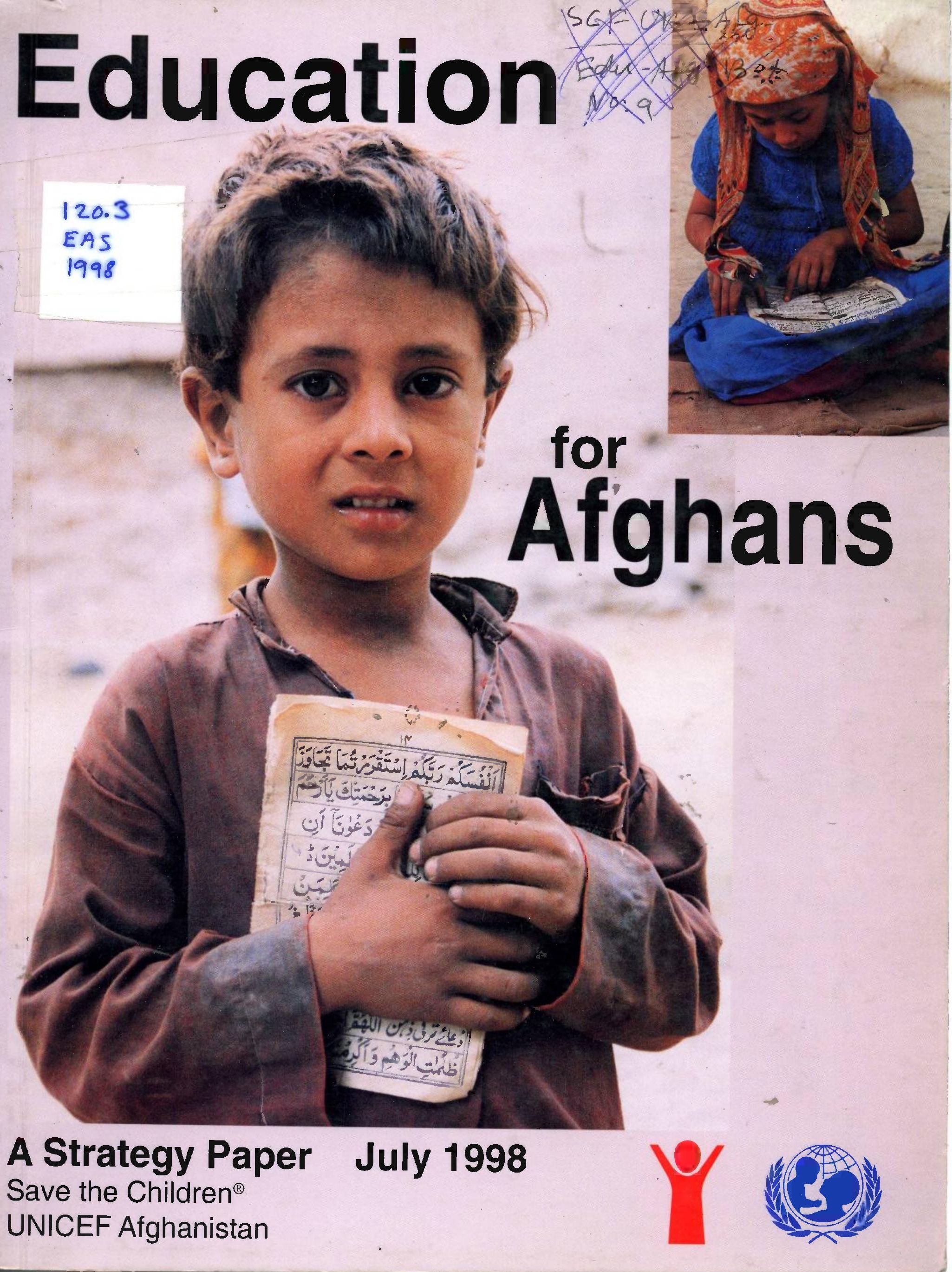




\title{
Education for Afghans
}

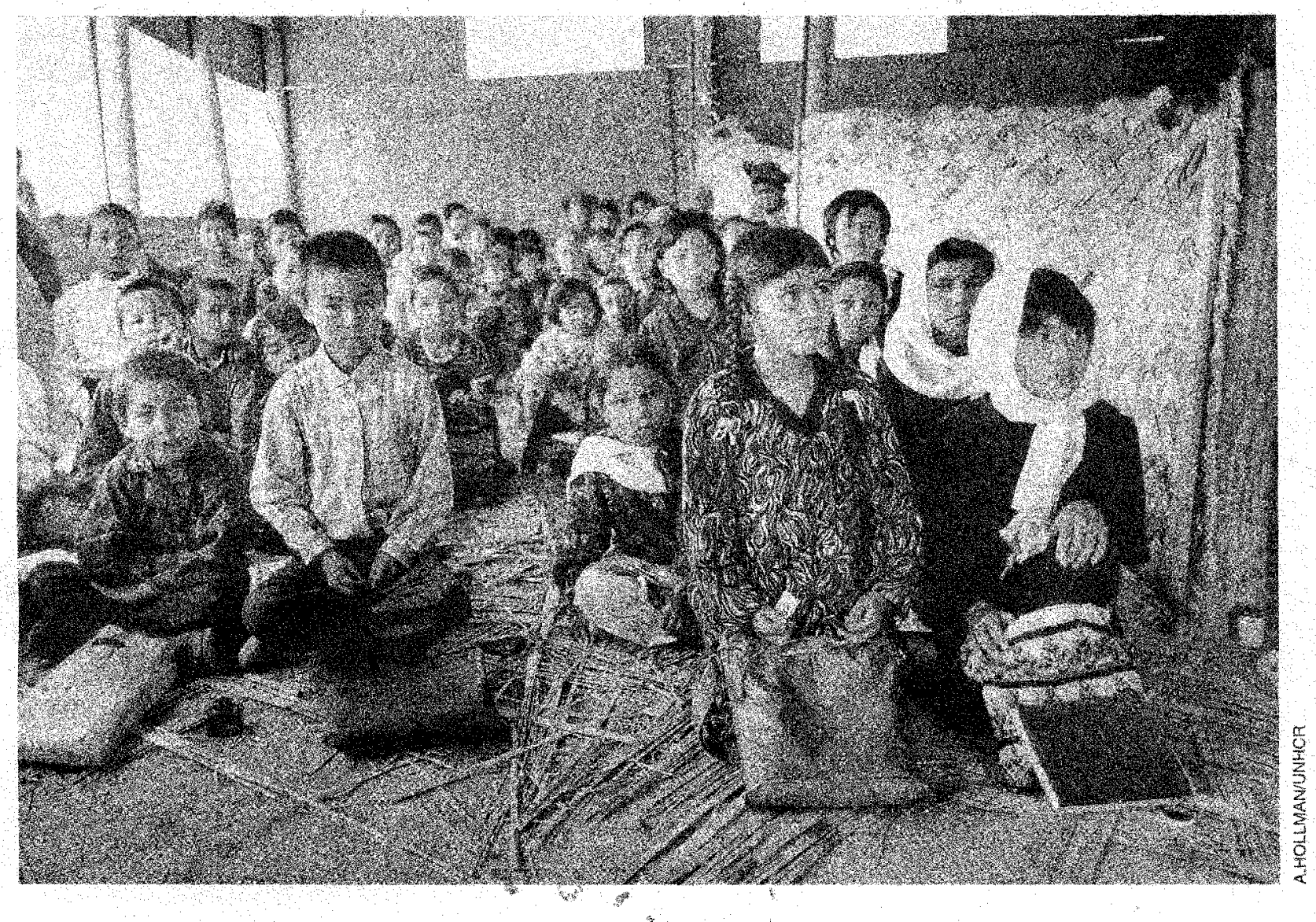

\section{A Strategy Paper July 1998}

\author{
by
}

Andrea $B_{w}$ Rugh, Ph.D.

Education Policy Consultant

Assisted by Hans Zomer

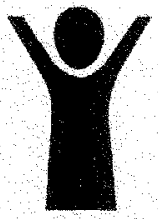

\author{
Save the Children $®$ \\ UNICEF Afghanistan \\ Supported by
}

The Royal Netherlands Embassy

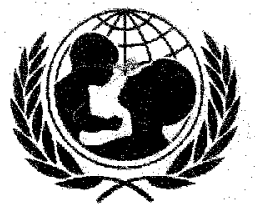




\section{CONTENTS}

Acknowledgements .............................................................................. ii

Executive Summary ............................................................................... iv

Introduction

Focus of the report

Strategies to improve access

Strategies to improve program quality

Strategies to strengthen capacity within the assistance community

Next steps

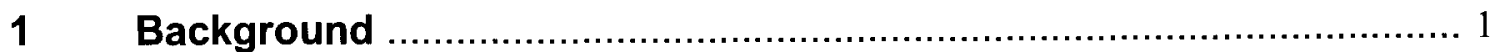

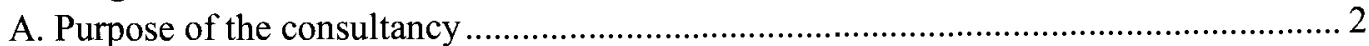

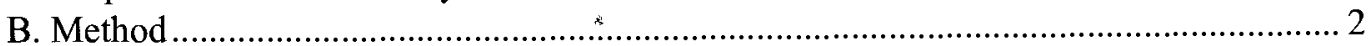

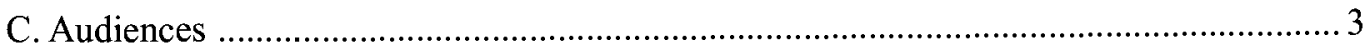

D. Organization of the paper .................................................................................. 3

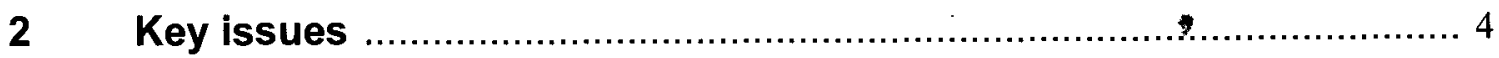

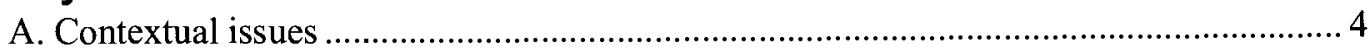

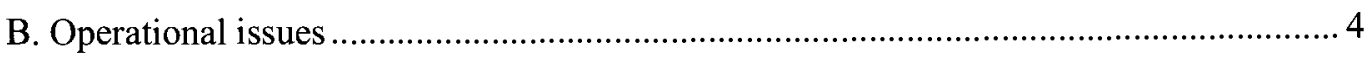

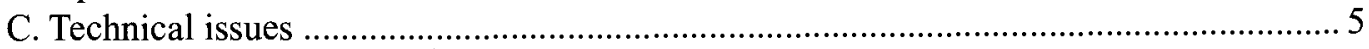

3 Capacities within the assistance community
A. Locations (coverage)
B. Types of programs
C. Targets
D. Technical experience
E. Summary of findings

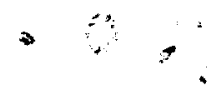

4 Perspectives on education objectives and approaches ................. 11

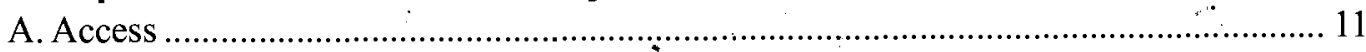

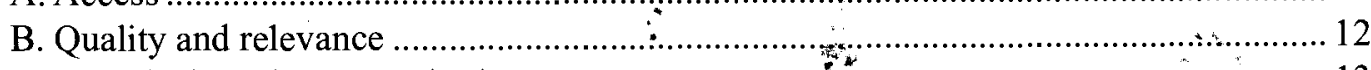

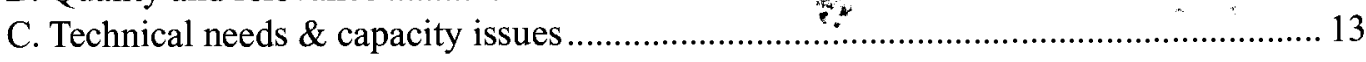

5 Strategies to maximize the impact of education assistance ............. 14

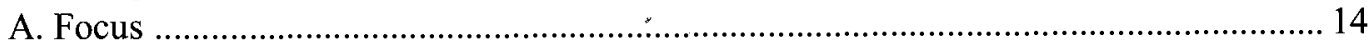

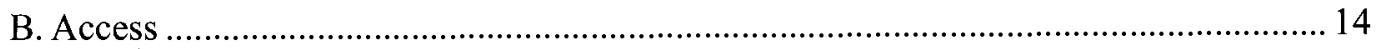

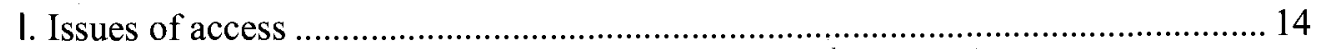

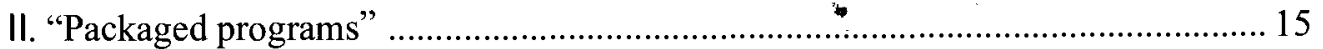

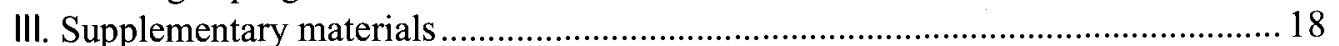

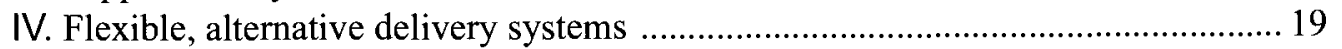

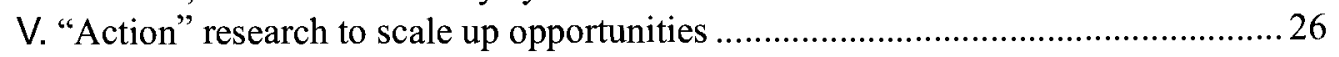

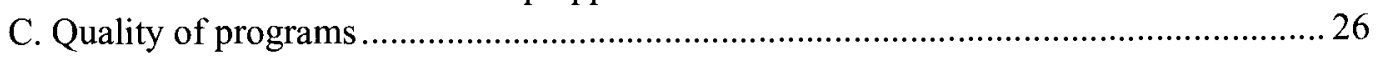

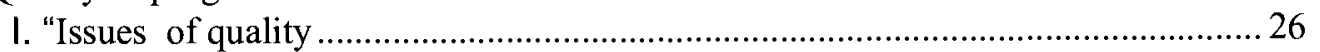

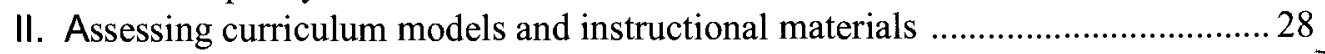

III. Immediate options for improving models .................................................... 29 


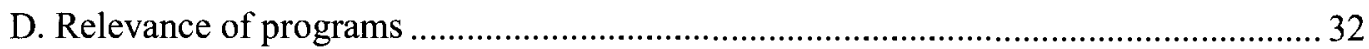

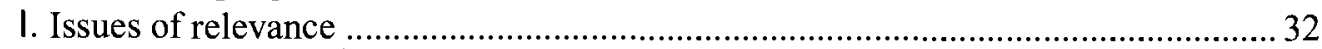

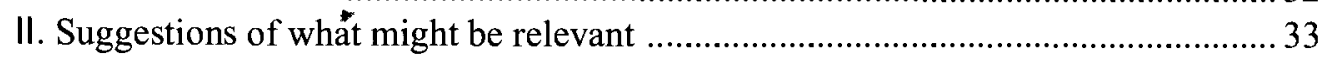

E. Strengthening capacity within the development community to support

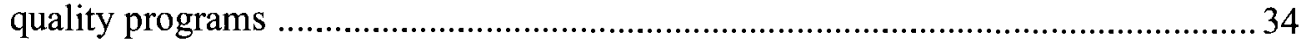

I. Capacity strengthening within the international assistance agencies ........................ 35

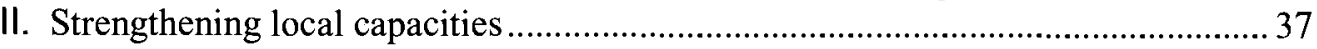

III. Capacity strengthening within Afghan formal education structures ....................... 38

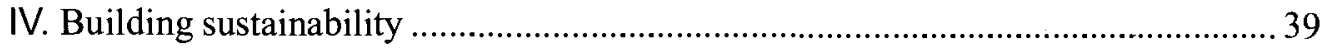

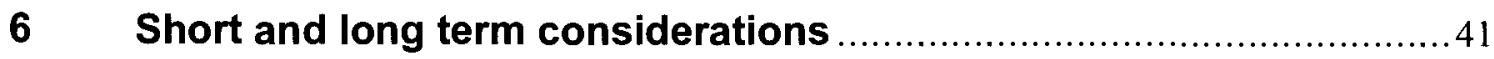

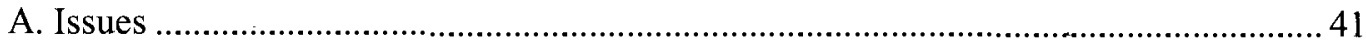

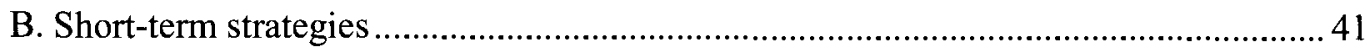

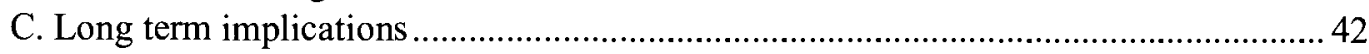

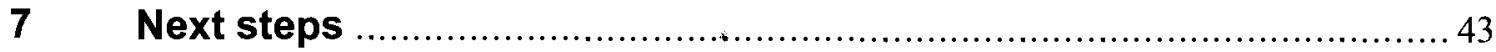

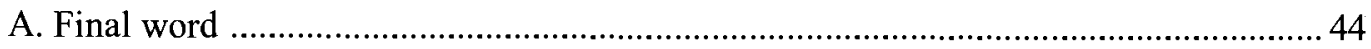

Summary of Technical Issues ......................................................... 45

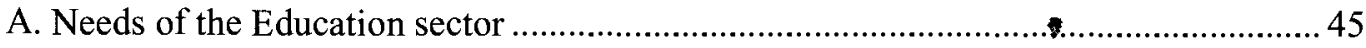

B. Strategies to maximize access to educational opportunities....................................... 45

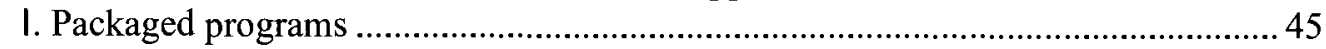

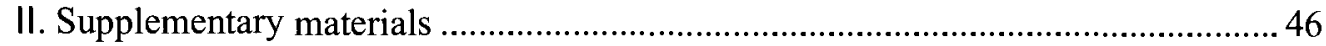

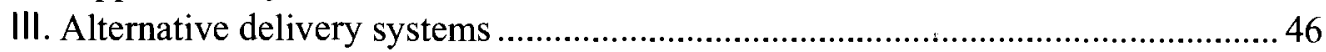

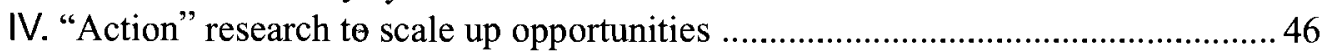

C. Strategies to improve the quality of education programs ............................................46

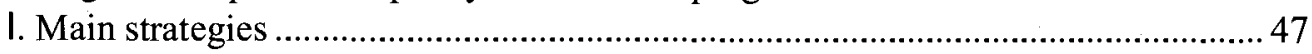

II. Other suggestions for improving program quality .............................................. 47

III. Increasing the relevance of education programs ................................................ 47

D. Strategies to strengthen capacity within the development community ........................48 48

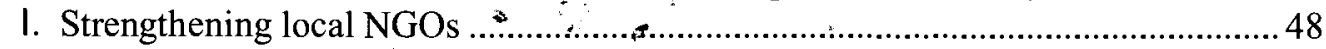

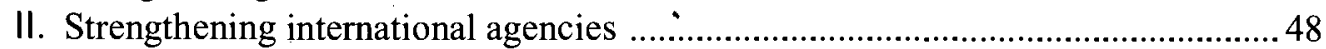

III. Strengthening capacity within Afghan formal education structures ...................... 48

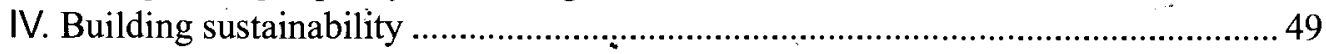

E. Short and long term aims of the assistance community ............................................ 49

\section{Annex 1: \\ Description of organizations and education projects ................................50}

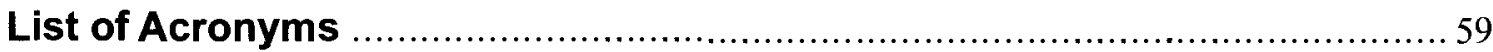




\section{ACKNOWLEDGEMENTS}

We would like to gratefully acknowledge the invaluable assistance provided by numerous agencies and individuals. All gave generously of their time to discuss programs and share perspectives and insights on Afghan education, often at short notice, and were willing to contribute project documentation. A number of agencies facilitated field visits to Afghan education programs in both Afghanistan and Pakistan, all adding greatly to our understanding of Afghan education.

We further wish to thank the initiators of the consultancy:

At Save the Children (USA), we would like to thank Andrew Wilder in particular, for direction, advice, comments on the draft of this report, and constant support. Catherine Kennedy organized meetings in Islamabad, and provided useful insights. We also wish to thank Milly Rao and other Save the Children staff for providing efficient administrative assistance. In Kabul, the support and hospitality of Kurt Tjossem and the Save the Children team were much appreciated.

We would like to thank Ellen van Kalmthout at UNICEF for her encouragement, coordination of field trips and meetings in Peshawar, and company during field visits in Afghanistan, as well as for her helpful comments on the draft report. Thanks are due also to the UNICEF staff in Peshawar for facilitating the visit to Afghanistan, as well as to UNICEF Kabul. The UNICEF office in Jalalabad organized field visits and provided generous Afghan hospitality.

We also would like to express our appreciation to the Royal Netherlands Embassy for supporting this consultancy, and especially to Govert Visser for his personal interest.

Finally, we would like to thank the many Afghan teachers and pupils in the classes visited.

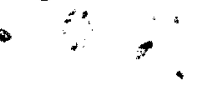

NOTE: The views expressed in this document are those of the author, and do not necessarily reflect those of Save the Children Federation, Inc. or UNICEF. 


\section{EXECUTIVE SUMMARY}

\section{Introduction}

The education sector in Afghanistan is in crisis. Even before the war educational opportunities were very limited, and few children were enrolled in schools outside the major towns and cities. During the last twenty years of prolonged conflict the education sector has suffered a series of further setbacks - destruction of much of its infrastructure, loss of many of its qualified staff, and governing authorities preoccupied with the war and unwilling to devote resources to the sector.

In any other context, the world community would recognize the urgency of the case, but the complexities of the war and the refugee situation have led the international assistance community to approach the sector cautiously. For almost two decades, support to education sector activities benefiting Afghans has generally been piecemeal and lacking in long-term vision..*

Now international attention is once again turned to Afghan education - this time in the context of human rights. It is an opportune time for the assistance community to renew its efforts to address the problems of the sector. Much can be done, within a principle-centered approach, to avert the dire consequences that will result if a generation of children go uneducated. This paper suggests strategies that, if implemented, will have both a short and long-term impact on improving the quantity and quality of education inputs.

\section{Focus of the report}

The consultancy which culminated in this report was supported by Save the Children (USA), UNICEF Afghanistan and the Royal Netherlands Embassy. It is one in a series of activities aimed at developing a more collaborative, informed approach to the education sector.

The report builds on earlier initiatives, in particuląr the workshop on "Education for Afghans: Issues Confronting the Assistance Community", which was erganized in Islamabad in April 1998 by Save the Children and UNICEF Afghanistan. A consensus emergèd from the workshop that the assistance community is faced with three categories of issues:

- contextual - the conditions of the Afghan situation which determine the limits of what can be done

- $\quad$ operational - the policy and funding constraints that affect the ability of agencies to carry out their initiatives $\quad .$.

- $\quad$ technical - the capacities and approaches of the assistance community required to realize an effective and efficient education program.

The contextual issues are largely outside the influence of the assistance community and the operational issues mainly involve the relations within and between agencies. These rektions are in a state of flux, with various funding and coordination mechanisms being designed and tried out at the moment. While these efforts are extremely important, the present report focuses on the more technical aspects of providing educational services and on strategies to improve the impact of international assistance to the Afghan education sector.

Irrespective of the operational context, more effective and flexible delivery methods and models need to be found to improve the provision of educational services to the Afghan people, whether in Afghanistan or Pakistan. The report's brief analysis of existing capacities within the assistance community makes itear that what is needed is a substantial improvement in access to and quality of education, as well as an increased capacity to develop and maintain education systems. The main issues addressed in this report are therefore, Access, Quality and Capacity. 


\section{Strategies to improve access}

The report identifies the following strategies that can lead to greater access to education:

- Assistance agencies should offer "packaged" programs which include the full range of essential $\therefore$ components - materials, training, supervision, and assessment.

- $\quad$ Agencies should produce low-cost supplementary materials to fill the gaps in existing education services.

- Agencies should develop flexible alternative delivery systems that address the conditions of urban and rural communities in different regions. Examples include home-based initiatives, communitybased initiatives, programs by local Afghan NGOs, Interactive Radio, self-instruction, roving teachers and mosque schools.

- More emphasis should be placed on "action research" to determine the most cost-effective way to scale up education opportunities and to assess the quality and cost-effectiveness of different assistance models.

\section{Strategies to improve program quality}

The major problems in the area of program quality relate to textbooks that are not designed with child learning in mind, ineffective teacher training and supervision systems that do not enhance teacher skills. The report recommends the following strategies to improve program quality:

- $\quad$ Assess the quality of curriculum models

- Improve supervision, focusing on learning outcomes

- Assess the system through continuous tests of student learning

- Develop the capacity to reflect and analyze among all education staff

- Develop mechanisms to focus initiatives on student learning, improvements in teacher training, better teacher support and "model elaborations" of lessons and instructional aids.

\section{Strategies to strengthen capacity within the assistance community}

In addition to focusing on quality and access, the aid community needs to strengthen its technical and delivery capacities and to increase the involvement of Afghans in education sector activities. Many international and national agencies do not have the capacity to plan and implement efficient and effective education programs. Furthermore, there is a lack of institutional memory among the assistance agencies and little consensus on the short and long-term aims of international assistance to education. *

The strengthening of capacity within local NGOs is particularly important. To this end, Afghan agencies need to improve their links with Afghan communities, as well as demonstrate their management capacities and ensure proper coordination. The international agencies on their side need to increase their own educational expertise, clarify responsibilities, help NGOs and, where possible, Afghan formal education structures to develop their capacities. While the short-term aim of international assistance to education should be to develop and test effective education models, in the long-term the international community should aim to deliver tested models efficiently and effectively to all children of Afghanistan. 


\section{Next steps}

The crisis in Afghan education is caused not only by the political context in the country, but also by a serious neglect of the quality, relevance and efficiency of the education provided. Though good examples can be found that might be expanded, assistance agencies at present have limited capacity to ensure a quality product or to bring their programs to scale. This report gives a number of practical suggestions on how assistance to Afghan education can be strengthened. It hopes to contribute to a process that will lead to agencies (NGOs, UN and donors) working together towards a common strategy for assistance to education.

The report focuses on practical steps that could be taken to increase the impact of assistance. Its recommendations can be implemented by individual agencies but a concerted and coordinated effort will have far greater benefits. A next step in the effort to improve the quality of international support for education would be a general planning exercise to determine the common strategy, as well as the roles that each individual agency can play within that strategy. What has also emerged is the need for a forum where those working in the education sector can share experiences, skills and lessons learned. Joint reflection and planning is of prime importance. The report therefore calls for a strengthening of coordinating capacities and for the creation of an informal forum for the sharing of experiences in the education sector.

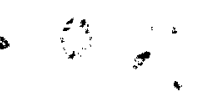




\section{BACKGROUND}

This consultancy was supported by Save the Children (USA), UNICEF Afghanistan and the Royal Netherlands Embassy. It is one in a series of steps aimed at developing a more collaborative, informed • approach to the crisis that confronts the Afghan education sector.

Afghanistan has one of the lowest rates of educational participation in the world. Where many other dèveloping countries are reaching 80 or 90 percent participation with almost equal rates for boys and girls, Afghanistan's statistics are so low and so unreliable that they are no longer officially reported internationally. It is estimated that approximately 3.6 million children are of primary school age inside Afghanistan. An estimated 1 million of these attended primary school in Afghanistan in 1995. It has been suggested that universal primary education in Afghanistan would require 10,000-20,000 schools. Yet, a 1993 survey counted 2,200 primary schools in 28 provinces, of which only 1,000 schools, enrolling 250,000 children are now being supported by international assistance. ${ }^{1}$ By comparison, of the estimated 230,000 Afghan children of primary school age in Pakistan, roughly 90,000 receive educational services through international assistance.

The situation of education in Afghanistan in every respect is a national emergency with little prospect of change in the near future. This same situation in another country without the complicating factors of continuing warfare and a difficult local authority would almost certainly have galvanized massive support from the international community. With roughly the same number of out-of-sohool children (4 million), Bangladesh, for instance, receives comparatively generous amounts of funding from the international community.

Important as education is to the future of Afghanistan, international assistance efforts until now have provided only a fraction of what is required to satisfy the needs for basic education. In addition, the services delivered are uneven, often of woefully poor quality and delivered with considerable inefficiency and cost. The fact that Afghan education constitutes an emergency does not mean the problem can be cured with short-term stop-gap aid. Assistance needs to be provided in a minimum of five year commitments if any kind of program capacity is to be developed.

Recent political events, including edicts by the Taliban banning girls' education and female employment, have attracted the attention of the international community again to the plight of Afghan children - this time in the context of human rights. This may prove an opportune time to raise important issues needing to be addressed, including the consequences if a generation of children go uneducated, or if the services provided do not benefit from the considerable international experience that has developed to improve the quality and efficiency of education programs. There is no reason, if carefufly planned, why short-term investment, even in a situation of uncertainty, cannot be reasonably assured of long-term applicability. In many respects the Afghan context provides excellent opportunities to create schooling models that can prove effective for a long time to come.

\section{The situation of education$$
\text { in Afghanistan in every respect }
$$$$
\text { is a national emergency }
$$

1 ACBAR Education Data Base 


\section{A. Purpose of the consultancy}

This consultancy began simultaneously with a one-day workshop held in Islamabad on April 30, 1998, attended by 40 representatives of major assistance agencies involved in education. The purpose of the workshop was to facilitate a process aimed at clarifying the overall objectives and strategies in the sector. As a next step this paper addresses technical issues surrounding potential future strategies for the assistance community.

The overall purpose of this consultancy was to assess international assistance to the education sector inside Afghanistan and in the diaspora, and to suggest strategies for maximizing the quality of impacts in the sector.

The paper assumes the political and policy contexts are too unstable to confidently describe or predict the conditions that will affect the assistance community's work in the near or distant future. However, we can no longer afford to let this uncertainty in Afghanistan prevent us from planning our strategies for future assistance to education (as has been the case for the last 20 years). Consequently, the paper confines itself to reviewing the extent to which the assistance community currently addresses key technical issues in the education sector and, given the general conditions of the Afghan context, seeks to identify which strategies might prove cost-effective in addressing a range of short and long term needs.

The specific objectives of the paper are:

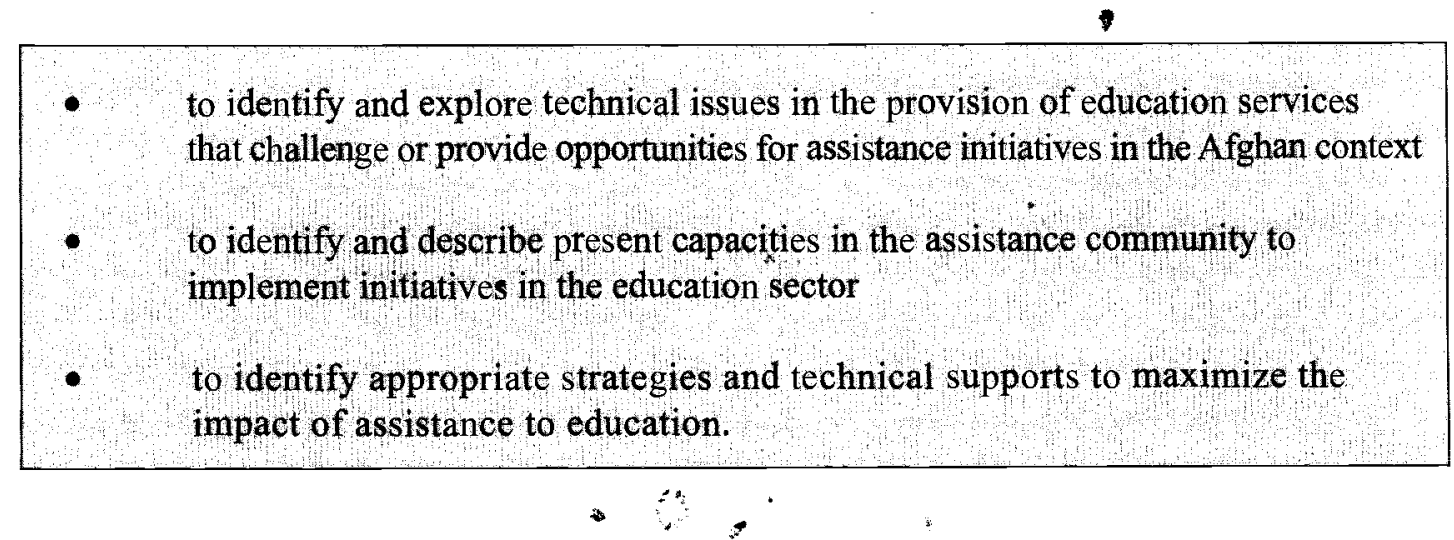

The logic of the approach is that by identifying key technical issues of the sector and the capacities of the assistance community to meet them, it will be possible to determine where present gaps exist. Once the gaps are known, they can be addressed by specific strategies to improve current and future initiatives in the sector. Although full reform of formal education may eventually be desirable in Afghan education, it is not the intent of this paper to suggest that the assistance community become involved in such a task at this time. Instead the paper identifies cost-effective strategies to improve the efficiency and quality of the programs now being provided through the assistance community. Due to time constraints, the paper focuses mainly on primary education and the various formal and non-formal channels through which it is delivered.

\section{B. Method}

This paper is based on a review of project documents, descriptions, proposals and other literature describing the current situation of Afghan education. A number of meetings were also held with representatives of assistance agencies and donors to solicit their views on technical issues, and to review the processes and products that comprise their initiatives in the education sector. Visits were made to a number of schools and projects in Kabul, Jalalabad and Kunar province inside Afghanistan, as well as in the refugee camps hear Peshawar. 


\section{Audiences}

The audiences for this report are primarily members of the assistance community - the agencies that implement and the funders that support activities in the education sector. They comprise a mixed group of funders, managers, development experts, technicians, decision makers and generalists. Because of this diverse audience, options are described in as concrete a way as possible so those not familiar with the technical aspects of the sector will understand their educational implications.

\section{Organization of the paper}

The paper is organized into seven parts including the Executive Summary and this "Background" section. The second section summarizes a number of key issues related to the assistance context. The third gives a brief overview of the coverage, targets, and capacities of the main assistance agencies. The fourth summarizes current views concerning approaches to the education sector and identifies the technical needs that will be addressed in the paper. The fifth section, which constitutes the bulk of the paper, provides suggestions to maximize the impact of education assistance. It covers the assistance community's aims of providing greater access, improving the quality and relevance of programs, and building capacities within assistance agencies to provide more services cost-effectively. The sixth describes the short and long-term implications of these strategies and the final section suggests next steps.

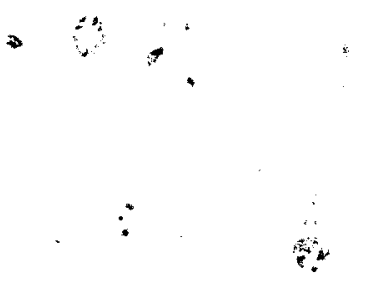




\section{KEY ISSUES}

Participants at the April 30th workshop in Islamabad raised three categories of issues confronting the assistance community: contextual, operational, and technical. Though some overlap, it is useful to separate them analytically. Below they have been summarized and expanded with information obtained from interviews and current literature on education initiatives in the Afghan community.

\section{A. Contextual issues}

Contextual issues refer to those conditions of the Afghan situation which provide opportunities and challenges to the assistance community, and determine the limits in some cases of what it is possible for them to do.

The opportunities include:

- the rising demand for education services, including for girls, especially in rural areas of Afghanistan and from Afghan refugees

- the experience of many Afghans in the diaspora that has left them valuing education

- $\quad$ community initiatives and willingness to support education programs

- a history of maintaining local institutions of learning in the form of mosque schools and madrasas

- a fluid situation that permits education initiatives to continue in many regions of the country despite official bans

- a renewed interest in Afghan education in the wider assistance community.

The challenges, not all of which are insurmountable, include:

- $\quad$ the low level of education in the pre-war period, and deterioration of the education infrastructure during decades-long hostilities

- the absence of government resources and support for the education sector, including materials, salaries, and facility construction, rebuilding and'repair

- the human rights issues involved in providing assistance with Taliban edicts against girls' education and female employment

- the lack of an authoritative presence with which to work in the education sector, and uncertainty about future directions in policy and support :

- uncertainty about where to strengthen capacity becaube of limitations in the structures of government

- a conservatism about girls' education in most parts of the country

- $\quad$ sustainability issues in the face of current conditions

- $\quad$ instability in the security situation.

\section{B. Operational issues}

Operational issues include those unresolved policy questions and the lack of resource inputs that affect the ability of assistance agencies to carry out education programs. Among these issues are:

- the role the assistance community should assume in the absence of government responsibility for the education sector

- the lack of a shared vision, approach, and set of strategies and principles, combined with a certain apprehension about a mechanism to coordinate efforts

- the lack of agreement on the advantages of alternative investment opportunities, such as investing in the refugee areas or inside Afghanistan 
- the limited, short-term nature of assistance and the often disruptive lack of funding continuity

- the sometimes inflexiblemandates of assistance support

- trade-offs in long-term sustainability vs. short-term effectiveness, as in support for teachers' salaries

- the absence of documented models, best practices and lessons learned that provide much needed practical experience

- the uncertainty about approaches to achieve economies of scale

- poor definition of short and long-term goals

- $\quad$ insufficient trust in local perspectives, capacities, and opportunities.

\section{Technical issues}

Technical issues refer to those capacities and approaches within the assistance community required to realize an effective and efficient education system. Among the specifically technical issues were:

- the development community's lack of technical expertise and experience in the education sector

- $\quad$ a fragmented approach that may not achieve the best results

- $\quad$ the absence of delivery mechanisms to scale up successful models

- the absence of measures to determine the effectiveness of programs

- $\quad$ insufficient capacity to continuously improve education inputs

- the need to develop sustainable programs.

Though the list of issues is long and complex, many can be addressed in whole or in part by technical means. Given the unpredictability of the situation in Afghanistan, it is appropriate to identify technical improvements that, while cognizant of conditions in the present situation, also serve over the long term to address quality and quantity issues in the Afghan context.

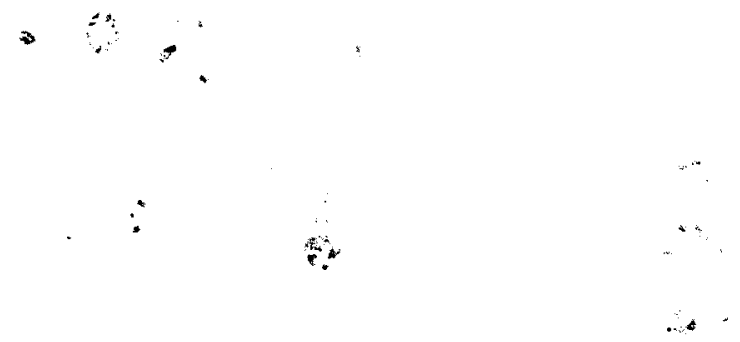




\section{CAPACITIES WITHIN THE ASSISTANCE COMMUNITY}

There are a large number of assistance agencies involved in the Afghan education sector. One indication of the problem confronting the education sector is that it proved very difficult to collect accurate data and information from all these agencies. The following section therefore, while not comprehensive, does summarize the experience of the main agencies in terms of geographical coverage, target beneficiaries, and technical skills. Descriptions of the agencies and their initiatives can be found in Annex 1.

\section{A. Locations (coverage)}

The following table indicates the geographical scope of the activities of 14 agencies, based on information provided by those agencies.

Although between them these agencies have projects in 25 of the country's 30 provinces, the table shows that the assistance is concentrated in a small part of the country: the NGOs mainly work in the provinces easily accessible from Pakistan (Paktia, Paktika, Nangarhar, Logar, Ghazni), as well as in Kabul. Approximately half of the 670 education projects mentioned in the 1996 ACBAR database were in these regions. In general, the South, Wèst, North and Hazara regions of Central Afghanistan are underserved.

\begin{tabular}{|c|c|c|c|c|c|c|c|c|c|c|c|c|c|c|c|}
\hline PROVINCE & ADA & BASEd & BEFARe & CARE & $\mathrm{CCA}$ & $\mathrm{HI}$ & IAM & IRC & NAC & $\mathrm{NCA}$ & NPO & OXFAM & SCA & SCF-UK & SC-US \\
\hline Badakhshan & & & & & & & & & $\bullet$ & & & & $\bullet$ & & \\
\hline \multicolumn{16}{|l|}{ Badghis } \\
\hline Baghlan & & & & & & & & & & & $\bullet$ & $\bullet$ & $\bullet$ & & \\
\hline Balkh & & & & & $\bullet$ & & & & & & $\bullet$ & $\bullet$ & $\bullet$ & $\bullet$ & $\bullet$ \\
\hline Bamyan & & & & & $\bullet$ & & & & & & & $\bullet$ & $\bullet$ & & \\
\hline Farah & $\bullet$ & & & & & & & & & & & & & & \\
\hline \multicolumn{16}{|l|}{ Faryab } \\
\hline Ghazni & & & & $\bullet$ & & & & & $\bullet$ & & & & $\bullet$ & & \\
\hline Ghor & & & & & & & & & & & & $\bullet$ & & & \\
\hline \multicolumn{16}{|l|}{ Helmand } \\
\hline Herat & $\bullet$ & & & & & & 6 & & & & & & & & \\
\hline \multicolumn{16}{|l|}{ Jawzjan } \\
\hline Kabul & 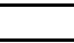 & & & 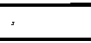 & & & $\bullet$ & $\bullet$ & $\bullet$ & $\bullet$ & & & $\bullet$ & & $\bullet$ \\
\hline Kandahar & $\bullet$ & & & & & $\bullet$ & & & - & & & & - & & \\
\hline Kapisa & & & & & & & $\therefore$ & & $\therefore$ & & & & $\bullet$ & & \\
\hline Kunar & & $\bullet$ & & & & & 7 & & $a_{i}$ & & & & $\bullet$ & & \\
\hline Kunduz & & & & & & & & & & & & & $\bullet$ & & \\
\hline Laghman & & $\bullet$ & & & & & & & & $\bullet$ & $\bullet$ & & 9 & & \\
\hline Logar & & & & $\bullet$ & & & & $\bullet$ & & & $\bullet$ & & $\bullet$ & & \\
\hline Nangarhar & & $\bullet$ & & $\bullet$ & & & & $\bullet$ & & $\bullet$ & & & $\bullet$ & & \\
\hline \multicolumn{16}{|l|}{ Nimroz } \\
\hline Oruzgan & $\bullet$ & & & & & & & & & & & & & & \\
\hline Pakteka & & & & & & & & $\bullet$ & & & & & $\bullet$ & & \\
\hline Paktia & & $\bullet$ & & $\bullet$ & & & $\bullet$ & $\bullet$ & & $\bullet$ & & & $\bullet$ & & \\
\hline Parwan & & & & & & & & & & 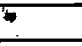 & & & $\bullet$ & & \\
\hline Samangan & & & & & & & & & & & & & $\bullet$ & & \\
\hline Takhar & & & & & & & & & & & & & $\bullet$ & & \\
\hline Wardak & $\bullet$ & & & & $\bullet$ & & & & & & & & $\bullet$ & & \\
\hline Zabul & - & & & & & & & & & & & & & & \\
\hline \multicolumn{16}{|l|}{ PAKISTAN } \\
\hline NWFP & & & $\bullet$ & $\bullet$ & & & & $\bullet$ & $\bullet$ & & & & & & $\bullet$ \\
\hline Baluchistan & & & & & & & & & & & & & & & $\bullet$ \\
\hline
\end{tabular}

NB. There are no exact data on the activities of the Afghan authorities' support to education. However, the Gowernment of Pakistan, in collaboration with UNHCR, supports refugee educaion in NWFP, Balochistan and Punjab. 


\section{B. Types of programs}

The table below is an attempt to categorize the activities of the various agencies. It is hoped that this table can serve as a brief inventory of agencies' capacities and experiences. The table is based on information frop different sources which made classification difficult. For instance, not all agencies make the same distinction between formal and non-formal education, or between secondary and primary/intermediate education. Also the distinction between primary education and literacy programs is not always clear.

What is clear, however, is that the overwhelming majority of programs include (formal) primary education or literacy classes. This would seem to be in line with general NGO experience and capacity. Most of these programs include their own teacher training efforts. Notable is the small number of agencies supporting Quranic schools or madrasas, the large number of skills training programs and the "alternative programs" of the BBC, Aschiana, SCF-UK and UNCHS.

\begin{tabular}{|c|c|c|c|c|c|c|c|c|}
\hline & $\begin{array}{l}\text { Primary } \\
\text { Formal }\end{array}$ & $\begin{array}{c}\text { Primary } \\
\text { Non-Formal }\end{array}$ & Secondary & Tertiary & Literacy & Construction & $\begin{array}{l}\text { Teacher } \\
\text { training }\end{array}$ & Special programs \\
\hline AAEA 、 & & & & & & $\bullet$ & & \\
\hline $\mathrm{ADA}$ & $\bullet$ & & & $\bullet$ & & $\bullet$ & $\bullet$ & Horticulture, Environment, Peace building \\
\hline AG-BASEd & $\bullet$ & & & & $\bullet$ & 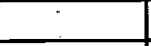 & & other \& Child health; Out of School children \\
\hline AITM & & & & & & & $\bullet$ & \\
\hline Aschiana & & & & & & & & Street children drama education \\
\hline $\mathrm{BBC}$ & & & & & & & & Radio drama; Informal radio education \\
\hline CARE & & $\bullet$ & & & & & $\bullet$ & \\
\hline GTZ-BEFARe & $\bullet$ & $\bullet$ & - & & & & & $\begin{array}{l}\text { Mine awareness; Community development; } \\
\text { Curriculum development }\end{array}$ \\
\hline $\mathrm{HI}$ & & & & & & & & Mine awareness \\
\hline IAM & $\bullet$ & & & & & & & Trainings for the blind; Skills training \\
\hline IIRO & $\bullet$ & & & $\bullet$ & & & & Quranic schools \\
\hline IKF & $\bullet$ & & & & $\bullet$ & & & Scholarships \\
\hline IRC & $\bullet$ & & & & & & $\bullet$ & Vocational training \\
\hline ISRA & $\bullet$ & & & $=0$ & $\therefore$ & & & Madrasa \\
\hline LBI & & & & & $F$ & * & $\bullet$ & \\
\hline LDI & & & $\bullet$ & & & & & \\
\hline MEDAIR & & $\bullet$ & & & & & & Teaching materials \\
\hline NAC & $\bullet$ & & $\bullet$ & $\bullet$ & & & $\bullet$ & Vocational training; Landmine education \\
\hline $\mathrm{NCA}$ & $\bullet$ & & & & $\therefore$ & 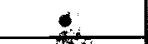 & & $\therefore$ \\
\hline NPO/RRAA & & & & & & 8 & & Integrated rural rehabilitation \\
\hline ov & $\bullet$ & & & & & $\bullet$ & $\bullet$ & Skills training \\
\hline OXFAM & $\bullet$ & & & & $\bullet$ & $\bullet$ & $\bullet$ & \\
\hline RALSA & & & & $\bullet$ & & & & \\
\hline SAB & & & & & 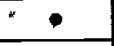 & & $\bullet$ & \\
\hline SCA & $\bullet$ & & & & $\bullet$ & $\bullet$ & $\bullet$ & Vocational training \\
\hline SCF-UK & & & & & & & & $\begin{array}{l}\text { Voice of Education media project; Children's rights } \\
\text { Health education in schools }\end{array}$ \\
\hline SC-US & $\bullet$ & $\bullet$ & & & $\bullet$ & & $\bullet$ & Out of school children; Landmine education \\
\hline UNO & & & & & & & & Curriculum devclopment, Textbooks \\
\hline UNCHS & & & & & $\bullet$ & & & "Community Fora" \\
\hline UNDP & & & & & & & & Radio education; Disabled program \\
\hline UNESCO & & $\bullet$ & & & $\bullet$ & & & Skills training \\
\hline UNHCR & $\bullet$ & $\bullet$ & & $\bullet$ & $\bullet$ & $\bullet$ & $\bullet$ & Vocational training \\
\hline UNICEF & & & & & & & $\bullet$ & Community developinent; Supply of materials \\
\hline UNOCHA & & & & & & & & Mine awareness \\
\hline UNOPS & & $\cdot$ & & & $\bullet$ & & & \\
\hline WFP & & & & & & & & Food supplies \\
\hline
\end{tabular}




\section{Targets}

The table below, compiled from information materials of agencies, gives an indication of the specific focus in the agencies' programs (more details can be found in the annex).

\begin{tabular}{|c|c|c|c|c|c|c|c|c|}
\hline & $\begin{array}{c}\text { Boys \& } \\
\text { Girls }\end{array}$ & Boys & Girls & $\begin{array}{c}\text { Not } \\
\text { specified }\end{array}$ & $\begin{array}{c}\text { Out of School } \\
\text { Children }\end{array}$ & $\begin{array}{l}\text { Illiterate } \\
\text { Women }\end{array}$ & Widows & Special groups \\
\hline AAEA & $\bullet$ & & & & & & & \\
\hline $\mathrm{ADA}$ & $\bullet$ & & & & & & & \\
\hline AG-BASEd & $\bullet$ & & & & $\bullet$ & $\bullet$ & & $\mathrm{MCH}$ \\
\hline Aschiana & & & & & $\bullet$ & & & \\
\hline $\mathrm{BBC}$ & $\bullet$ & & & & & & & \\
\hline BRR & & & & $\bullet$ & & & & Peace pioneers \\
\hline CARE & $\bullet$ & & & & & 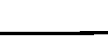 & & \\
\hline $\mathrm{CCA}$ & $\bullet$ & & & & & $\bullet$ & & Human rights activists, Teachers \& Media \\
\hline GTZ-BEFARe & $\bullet$ & & & & $\bullet$ & $\bullet$ & & Illiterate adults \\
\hline $\mathrm{HI}$ & & & & $\bullet$ & & & & Disabled; Landmine victims \\
\hline IAM & & & & $\bullet$ & & & & Blind; physiotherapists \\
\hline IRO & & & & $\bullet$ & & & & \\
\hline$\underline{\mathrm{IKF}}$ & & & & $\bullet$ & & $\bullet$ & 9 & \\
\hline IRC & & & $\bullet$ & & & $\bullet$ & & \\
\hline ISRA & & & & $\bullet$ & & & & \\
\hline \multicolumn{9}{|l|}{ LBI } \\
\hline LDI & & $\bullet$ & $\bullet$ & & & & & \\
\hline MEDAIR & - & & $\bullet$ & & & & & \\
\hline NAC & $\bullet$ & & $\bullet$ & & & & & Former soldiers; Handicapped; Returnees \\
\hline $\mathrm{NCA}$ & $\bullet$ & $\bullet$ & $\bullet$ & & & & & \\
\hline NPO/RRAA & $\bullet$ & & & & & & & \\
\hline ov & $\bullet$ & & & & & . & $\bullet$ & Disabled, Returnees \\
\hline OXFAM & $\bullet$ & & & & & $\bullet$ & & \\
\hline RALSA & 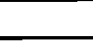 & $\bullet(*)$ & & & & & & Health professionals \\
\hline SAB & $\bullet$ & & & & & . & & Illiterate adults; Teachers \\
\hline SCA & $\bullet$ & & & $\$$ & - & $\bullet$ & & \\
\hline SCF-UK & $\bullet$ & & $\bullet$ & & 4 & & & \\
\hline SC-US & $\bullet$ & & & & $\bullet$ & $\bullet$ & & \\
\hline UNO & & & & $\bullet$ & & & & \\
\hline UNCHS & & & & $\bullet$ & $\therefore$ & & & \\
\hline UNDP & $\bullet$ & & & & $\div$ & 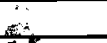 & & Disabled - \\
\hline UNESCO & $\bullet$ & & & & & $\because \bullet$ & & Illiterate adults; Returnees \\
\hline UNHCR & $\bullet$ & $\bullet$ & $\bullet$ & & $\bullet$ & $\bullet$ & & Illiterate adults, $\mathrm{MCH}$, Disabled, Adolescents \\
\hline UNICEF & $\bullet$ & & & & & & & \\
\hline UNOCHA & & & & $\bullet$ & & & & \\
\hline UNOPS & & & & & $\bullet$ & $\bullet$ & & \\
\hline
\end{tabular}

$\left.{ }^{*}\right)$ refers to projects temporarily open to boys only.

While it is clear that the majority of agencies focus on education for boys and girls, there are several organizations that target only girls or boys. Most agencies try to retain a balance, by having boys-only programs co-exist with girls-only programs (exceptions include IRC, MEDAIR and RALSA). The information material from nine organizations did not indicate a specific gender focus. 
While only one organization focuses specifically on widows, several others have identified disabled people and illiterate adults as special target groups. BRR (peace pioneers), IAM (blind) and CCA (human rights activists) have special target groups that are not mentioned by any of the other agencies. The categories "illiterate women" and "illiterate adults" are not mutually exclusive, as usage of the terms varies by agency.

\section{Technical experience}

The following table is an attempt to chart some of the existing capacities in the assistance community. Based on the information in the above tables and from conversations with a range of actors, this table gives a summary of the capacities of 13 agencies active in the education sector. The list of agencies is not intended to be comprehensive, but does represent most of the major agencies working in the education sector.

The table indicates that, while there are many efforts in the field of teacher training, only a limited number of organizations actually assess the impact of their programs in terms of student learning. Furthermore, most organizations do monitor the schools/programs they support, but not all of them have engaged in in-depth evaluations of, and reflection on, their efforts.

\begin{tabular}{|c|c|c|c|c|c|c|c|c|c|c|c|c|c|}
\hline & $\begin{array}{l}\text { A } \\
\text { D } \\
\text { A }\end{array}$ & $\begin{array}{l}\text { B } \\
\text { A } \\
\text { S } \\
\text { E } \\
\text { d }\end{array}$ & $\begin{array}{l}\mathrm{B} \\
\mathrm{B} \\
\mathrm{C}\end{array}$ & $\begin{array}{l}\mathrm{B} \\
\mathrm{E} \\
\mathrm{F} \\
\mathrm{A} \\
\mathrm{R} \\
\mathrm{e}\end{array}$ & $\begin{array}{l}\mathrm{C} \\
\mathrm{A} \\
\mathrm{R} \\
\mathrm{E}\end{array}$ & $\begin{array}{l}\mathrm{I} \\
\mathrm{R} \\
\mathrm{C}\end{array}$ & $\begin{array}{l}\mathrm{N} \\
\mathrm{A} \\
\mathrm{C}\end{array}$ & $\begin{array}{l}\mathrm{O} \\
\mathrm{X} \\
\mathrm{F} \\
\mathrm{A} \\
\mathrm{M}\end{array}$ & $\stackrel{\mathrm{O}}{\mathrm{V}}$ & $\begin{array}{l}\mathrm{S} \\
\mathrm{C} \\
\mathrm{A}\end{array}$ & $\begin{array}{l}\mathrm{S} \\
\mathrm{C} \\
- \\
\mathrm{U} \\
\mathrm{S}\end{array}$ & $\begin{array}{l}\mathrm{U} \\
\mathrm{N} \\
\mathrm{H} \\
\mathrm{C} \\
\mathrm{R}\end{array}$ & $\begin{array}{c}\mathrm{U} \\
\mathrm{N} \\
\mathrm{I} \\
\mathrm{C} \\
\mathrm{E} \\
\mathrm{F}\end{array}$ \\
\hline Community Support & $\bullet$ & & & & $\bullet$ & $\bullet$ & - & $\bullet$ & & $\bullet$ & $\bullet$ & & $\bullet$ \\
\hline School management & - & & & & & $\bullet$ & & & & - & $\bullet$ & & \\
\hline Curriculum development & & & & $\bullet$ & & & & & & & & & \\
\hline $\begin{array}{l}\text { Instructional materials } \\
\text { development }\end{array}$ & & - & 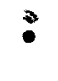 & $\because$ & 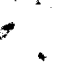 & • & & & & • & • & & \\
\hline Teacher training & - & - & & $\bullet$ & $\bullet$ & $\bullet$ & $\bullet$ & $\bullet$ & $\bullet$ & $\bullet$ & $\bullet$ & & $\bullet$ \\
\hline Monitoring and supervision & & $\bullet$ & & $\bullet$ & - & $\bullet$ & & - & $\bullet$ & $\bullet$ & $\bullet$ & & \\
\hline $\begin{array}{l}\text { Assessment of student } \\
\text { achievement }\end{array}$ & & $\bullet$ & & - & • & ? & & & & . & • & & \\
\hline Evaluation & & $\bullet$ & $\bullet$ & $\bullet$ & $\bullet$ & & & $\bullet$ & & $\because$ & $\bullet$ & & $\bullet$ \\
\hline Alternative delivery & & & $\bullet$ & & & & & & & & $\bullet$ & $\bullet$ & $\bullet$ \\
\hline Construction & $\bullet$ & & & & & & $\bullet$ & $\bullet$ & $\bullet$ & $\bullet$ & & $\bullet$ & \\
\hline
\end{tabular}




\section{E. Summary of findings}

Overall, the assistance agencies show a significant coverage in terms of geography and target groups in Eastern Afghanistan, but other regions are generally underserved. The number of beneficiaries the agencies serve are small which suggests the need to enhance capacity and develop more efficient ${ }^{\circ}$ delivéry systems. Finally, areas of technical experience vary. Many agencies are involved in teacher training and supervision, while only one develops curriculum materials and few systematically assess student learning outcomes. 


\section{PERSPECTIVES ON EDUCATION OBJECTIVES AND APPROACHES}

At the workshop in Islamabad, the participants described the objectives of their education initiatives. Though covering a wide range of specific aims, they all fell within the following three conventional rubrics:

- $\quad$ increasing access

- improving quality and relevance

- $\quad$ strengthening capacity to develop, implement, and maintain education initiatives.

Speaking from both personal and organizational perspectives, the representatives divided on the approaches that should be taken to address issues within the sector. Some of these perspectives are described below.

\section{A. Access}

Access was an issue that dominated discussions. Many participants saw opportunities to provide "principled" assistance in the current climate of increasing demand for education services both inside Afghanistan and in refugee communities. They felt the Taliban ban on girls' education and female employment was not a major constraint on the education sector except in urban areas, and believed communities in many regions of the country were able to support education services for both boys and girls. They noted especially the opportunities to work in those northern areas not under Taliban control. They pointed out that there had been very little participation of girls in rural areas even before the edict, and that to frustrate the rising demand for education was to jeopardize the development of society and to encourage.Afghans to retreat into the diaspora again. In general, many felt that a gradual non-confrontational approach to the Taliban would be more effective in the long run in reaching latge groups of children, especially in rural areas. They felt opportunities should be seized as they became available.

Some also expressed the view that, especially in urban areas where its effects were more apparent, the Taliban's edict banning female education and employment had to be confronted on principle. This view focused on human rights issues and being abte tó operate openly to bring education services to large numbers of beneficiaries. It was felt that scale could best be realized through a principled public stand against the edicts that might lead to their relaxation and thus scope to expand activities. Many felt, however, that although agencies should not work in the formal sector out of concern for human rights principles, other alternative non-discriminatory channels such as home-schools in urban areas and community-based initiatives in rural areas should be supported. There was general unanimity that basic primary schooling should be the main priority, but some warned that we could not neglect secondary and tertiary schooling without jeopardizing the country's need for professionals in the future.

Some felt that the high demand for education in refugee camps outside Afghanistan makes them an ideal location to support education programs, especially for girls, until it becomes easier to work inside the country. The alternative argument was that improving services for refugees would prevent them from repatriating, and that establishing schools inside Afghanistan would provide a greater incentive for their return. Many, especially Afghans, felt mystified by the assistance community's declining support for the refugee community in Pakistan where it is now estimated that approximately 216,000 primary school age Afghan children reside. ${ }^{2}$ The supportive environment for education in the refugee communities, they believed, makes them a more conducive place to strengthen the skills and capacities of education personnel who might some day return to the country. Their argument highlights a considerable cross-border influence on education programs in terms of demand, teaching methods and other improvements.

$\overline{2 \text { Rough estimates suggest that about half these children receive an education. }}$ 


\section{B. Quality and relevance}

Although quality was sometimes mentioned as an objective of project activities, people tended to be more preoccupied with increasing the numbers of children in school. Quality may have been a secondary issue largely because most assistance staff are managers and administrators of projects, and not educators. Often they did not distinguish clearly between needs and approaches, seeing access as a question of numbers and service delivery, and quality as a question of service delivery plus other tangible inputs such as training. Although somewhat understandable in the current situation of emergency assistance and poor access, paying insufficient attention to quality issues can have devastating effects on children's learning and whether they acquire basic functional skills.

Many admitted in conversations that they possessed little expertise in the area of quality programming and therefore referred such questions to those who developed instructional materials and training. Some felt that quality was a luxury during this "emergency" period, and that some form of education was better than none. One person interviewed expressed the view that since research had demonstrated the positive relationship between development indicators and education level, regardless of program quality, that this issue should not be of major concern. Some simply felt that improvements would be costly and take too long to realize within the time frame of their projects. Many simply did not know what quality improvements would entail, or felt it was too controversial an issue for them to address directly. Afghans expressed the strongest concern both as parents and as professionals concerned with the future of their country. The felt especially that the quality of the present education inputs, especially materials and training, were poor and did not produce relevant or effective learning.

Agencies varied considerably in the way they approached program quality: from providing materials only, to providing writing supplies materials and some training, to providing a complete package of these inputs plus considerable support in monitoring and supervision. A few therefore viewed the quality of programs from a holistic perspective where all inputs needed to be present to have an effectively functioning system. A few felt the inputs needed to be refined if quality was to improve, but few had the capacities within their organizations to effect these refinements.

Most who expressed an opinion on the quality, of their programs were resigned to using available instructional supports in the absence of effective institutional capacity to organize new and better curricula and materials. Some felt there was little need to improve materials since the main criterion for their selection should be their approval by authorities. Often communities asked for these approved materials because their teachers were familiar with them, and agencies saw no reason hot to provide them. Others simply based their selection of materials on which were the cheapest. Very few agencies madde any effort to assess the effectiveness of materials on how well they helped children to learn (and there are major observable differences!).

Often poor quality was blamed on the inadequacies of teachers who were said to be ill-equipped academically and not sufficiently trained. Some felt a need to improve teacher training, though normally the solution proposed was more and better training although no one was quite sure what "better" training would require. In general there was little satisfaction with the training that exists.

Relevance for the most part was addressed mainly as the importance of providing all levels of education, or as content gaps in the study of languages or in timely topics such as the environment, peace, negotiating skills, etc.

The differences, which are perhaps understandable in terms of how various individuals experience the development context, are nevertheless important in determining which strategies will be seen as effectively addressing the issues of the sector. It is not the aim of this paper to judge these perspectives as right or wrong, but rather to take them as constraints or opportunities to operationalize effective strategies. 


\section{Technical needs \& capacity issues}

Given the variety of views expressed above, it seems useful to identify cross-cutting technical needs and capacity issues not limited by any single perspective or approach. These include:

- more systemic approaches to the provision of education services, including a stronger emphasis on achieving desired outcomes

- more effective, flexible delivery methods and models that can serve the needs of children in the various contexts of Afghanistan and the diaspora

- $\quad$ attention to issues of long-term sustainability of education programs;

- $\quad$ strengthened capacity within the international assistance community to support quality programs

- $\quad$ strengthened capacity within local education structures and NGO agencies to assume eventual responsibility for the education sector.

The following section addresses these needs with recommended strategies.

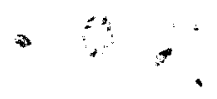




\section{STRATEGIES TO MAXIMIZE THE IMPACT OF EDUCATION ASSISTANCE}

\section{A. Focus}

The paper focuses on the following three education objectives raised during the Islamabad workshop:

\section{Increased access}

Improved quality and relevance

Strengthening of capacities to develop, implement and

maintain education systems and structures

This section proposes strategies that might be applied to maximize the impact of international assistance in each of these areas. All are important in improving impacts in the education sector, but even when only some are selectẹd for implementation they can also play an incremental role in improving overall outcomes. Education components constitute a system which are synergistic in their relationships. Therefore, the more they relate effectively to one another, the greater the likelihood of maximizing results.

The intent below is to suggest strategies that are practical and inexpensive, and which build on existing components as much as possible. Most can prove useful in achieving long-term goals, as well as reaping short-term benefits. The operationalization of many will have the residual benefit of strengthening capacities within the local and international community to execute quality education programs over the long-term.

\section{B. Access}

\section{Issues of access}

Access in the international literature is often defined rather broadly as a child's ability to participate in education programs. The definition includes the implications of having nearby facilities for education, being able to go regularly, to stay in school and to complete various stages. It implies that conditions in the home environment and the community are such that the child is permitted to attend, and consequently school conditions must be such that parents are willing to let children gev to school. In many cases, access also implies that there are no barriers to schooling that result from preventable physical or nutritional deficiencies. Indicators of access include participation rates (out of total children in the age group), total enrollments, ratio of children enrolled (to determine gender gaps), attendance rates, repetition (often an early indicator of dropout), drop-out, and completion rates. In the Afghan context, the attention of the assistance community is almost entirely preoccupied with simple enrollment rates.

The situation is made more difficult in Afghanistan by the fact that historically (though at one time there may have been more and better infrastructure for providing "modern" education) educational services were mostly concentrated in towns and cities, and therefore large areas of the countryside went largely unserved. Girls' education was unheard of in many of these areas, and even in urban areas there were large differences between the participation rates of girls and boys. The fact that there now is a rising demand for girls' education both among Afghans inside Afghanistan and those still in the refugee community, makes it doubly tragic that resources and capacities are not adequate to support this interest. 
In Afghanistan there are no easy answers. The international assistance community itself is divided on how it believes it should support acces to education. There is universal agreement on the need for more accessible educational opportunities for children, especially those who have been educationally disadvantaged, but disagreement on how these opportunities can be most effectively provided (see above).

Some of the specific questions being raised about access that may be addressed by technical responses include:

- Do non-formal opportunities offered to girls provide an education equivalent in quality to formal schools, and is this an adequate education in general?

- $\quad$ Are three years enough time to develop the skills children need to cope as adults, or can opportunities be provided to extend this education further?

- How can differences in education contexts (urban, rural, multiple ages and abilities, refugee and repatriate) be addressed effectively through delivery mechanisms?

- In a time of limited resources, can more opportunities be eked out of less, and where should scarce resources be targeted?

- How can the present limited initiatives be brought to scale?

- How can Afghans be given a larger role in deciding what and how benefits are distributed?

These and many other issues surround the problem of delivering education services to Afghans. They call for creative approaches to the question of access, in terms of venue as well as in the means of delivering education.

If one assumes current budget levels or modest increases - making it impossible to meet more than a fraction of demand - the only way to increase participation significantly will be to obtain greater efficiencies in the way education programs are packaged and distributed. Even if the kind of massive aid needed is forthcoming to meet current and future demand, efficiencies of the kind described below will be required to manage the distribution of education programs brought to scale.

Four suggestions are made below to improve the efficiencies of delivery:

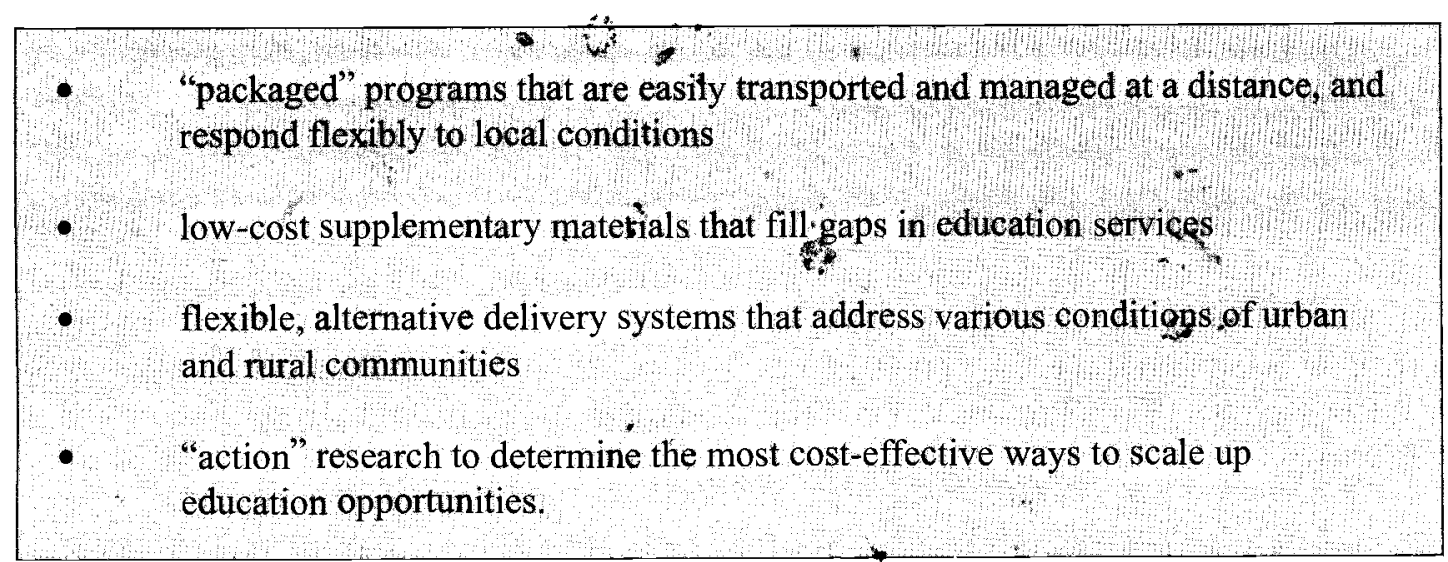

\section{Access: "Packaged programs"}

\section{a. Lessons learned}

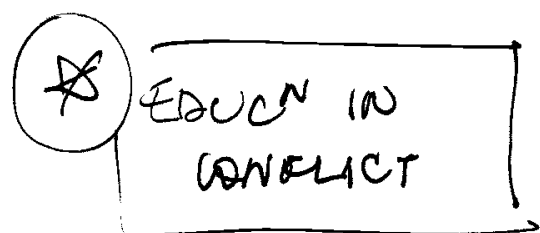

Traditionally education services are developed and directed by a central authority, usually a Ministry of Education, that determines the content of education, the kinds of training and supervision required, and the means and standards by which students will be judged and eventually accorded certification. This authority also determines the extent to which education opportunities are supplied and whether students should be 
compelled to attend. With few exceptions in the world, "modern" education systems are rarely provided entirely through initiatives originated in or carried out by communities themselves.

One such exception is Kenya where, as a result of insufficient places, rural parents have constructed schools, hired teachers and bought government instructional materials to enable their children to receive a secondary education. The weaknesses in these Kenyan schools are instructive for the Afghan case. First, they are of generally poor quality - many were unable to engage expertise productively to ensure the quality of their programs, and the existing materials to which they had access were not designed to be used without extensive human and material support. Thus they frustrated parents' expectations of providing more options for their children in entering higher education stages and better employment. Second, the provision of education opportunities concentrated in regions of the country where parents could afford to support them, however minimally, and left poorer areas without any access to education opportunities. The little help the government eventually provided dissipated MOE resources and made it impossible for the government to right the balance in poorer communities. The Kenyan case suggests that communities have difficulty maintaining a quality program on their own, and that expecting communities to finance their own systems leads to different opportunities for rich and poor communities.

Afghanistan's case is more critical than Kenya's in that the authorities are unable or unwilling to support even the most basic education services, and that the quality in unassisted schools has deteriorated to a greater degree. The response to these problems from the assistance community has until now been ad hoc and piecemeal, with the provision of core instructional materials selected more for the practical reason that they are approved by the authorities than that they have been proven effective. Several school programs were developed a number of years ago under different conditions, none were developed intentionally to stand independently as an Afghan curriculum and most require intensive support to install and maintain them. None of the programs comes in a complete package tested for the effectiveness of each of its components, and easily implemented with minimum support. None addresses the variable conditions that exist in cities, towns and villages of Afghanistan or in existing classroom contexts.

\section{b. Packaged programs - Rationale}

\section{Packaged instruction as proposed here is defined as an instruction which has all of its essential elements carefully designed for the convènient use of its customers, whether fully qualified in the education profession or not, whether living in urbaì or rural communities, or whether in non-formal or formal classrooms.}

It tends to be cost-effective because it needs minimum support Packaged instruction does not need to be rigid or mechanistic, but it should be adaptable for use both in conventional schooling, and under conditions where schooling is accelerated, shortened or in other ways made more convenient to the circumastances of those who use it. Its purpose is to provide a proven program in as simple, self-evident and user-friendly form as possible with a comprehensive set of components so that even the most unskilled practitioner can use it with minimal training. Safeguards in the form of assessment and monitoring systems are included to ensure its effective use.

Because developers of instructional materials normally do not address the questions of transportability and usability by unskilled practitioners, it is necessary to review existing programs keeping these aims in mind. The currently existing programs used in the Afghan context tend to be labor-intensive with regard to training and monitoring - at least partly because they deviate so considerably from local teachers' experience with teaching/learning behaviors. This does not mean that the new behaviors are necessarily undesirable, but it does mean that they must be translated for teachers in a clear and simple manner. The existing programs are also not easily adapted to a variety of teaching/learning conditions. That is, they may not be entirely suitable in environments where the school day is shortened, children need to be absent for periods of time, orwhere children must be prepared to go on to higher stages of learning if that becomes desirable. 


\section{c. Packaged programs - Approach}

To develop a packaged program in the current context would require several steps in its most elaborated form:

- $\quad$ Agreement by the providers of education services that this would be a useful step, and provisfonal agreement from the agencies that they would be willing to use the packages once prepared.

- A determination of criteria to be used in adapting existing programs to the needs described above, and a brainstorming session with providers of education services and field workers to determine the constraints/opportunities in the various contexts (urban/rural, refugee, inside Afghanistan) that need to be addressed. The outcome of this meeting or of a follow-on study would be a needs framework for the packages. For example, the recommendations might include criteria for the variability of conditions in which the package would be used, the qualifications of the users, the coverage of essential subject content to be delivered, and an indication of the content of the packages (possibly to include a set of instructional materials, self-evident teachers' notes with simple, but detailed lesson plans to accompany a student text, assessment instruments, record keeping forms and supervisors' proformas).

- An assessment of existing curriculum materials and their support mechanisms. The assessment would cover the main "models" in use now from the perspective of acceptability in terms of pedagogy, Afghan local aspirations, usability in the Afghan context, transportability, maintenance requirements, Gosts, and learning impacts. The outcome of the assessment would be a report on how these models might be modified to conform to the needs of providers in terms of portability and ease of use or, alternatively, on what kind of program might be created to satisfy the intentions.

- A commitment to make the changes, appointment of appropriate individuals to take responsibility for the changes, and a combined support from the assistance community to make it possible.

- $\quad$ Field-testing the packages under the range of circumstances where they might be used to determine whether they effectively meet the specifications of the providers. Modifying the packages as indicated, and disseminating them to appropriate audiences.

Though providers may resist such an approach on the grounds of cost, effort and a belief that quality is a luxury, they should remember the considerable investment that has gone into teacher training in the Afghan context with little or no proven effect on student learning. Similarly, it is a fact of good education programming that curriculum materials and their supportive systems - teacher training, supervision, and assessment - should be subject to continuous improvement and review and that modifications of components should be based on their capacity to improve student outcomes by addressing constraints in the learning environment. A packaged program in effect can be created in a number of forms ranging from the most simple to the most elaborate. The main considerations, if existing components are used, are that all of them are assessed and modified in terms of effectiveness, transportabiliț and useability in various contexts and with a variety of practitioners.

\section{d. Packaged programs - Possible elements}

To develop effective self-standing packages from existing materials/models may require inputs like those described below that fill gaps in the models:

$$
\begin{aligned}
& \text { - objectives so that each student textbook lesson makes clear what competency is being taught } \\
& \text { teacher notes/guides to accompany student texts with simple detailed lesson plans showing } \\
& \text { teachers how to teach each unit of work } \\
& \text { lesson plans in the notes or guides structured around a predetermined set of effective } \\
& \text { teaching steps to simplify the process of teacher training (teachers learn the pattern in a } 1 \\
& \text { or } 2 \text { day training) } \\
& \text { sets of test items from which a monitor or supervisor can prepare tests to assess student } \\
& \text { learning results } \\
& \text { - }
\end{aligned}
$$

3 Some books now in use, for example, teach beginning students to count to 10 in the space of a page or two. Teacher notes might show how to elaborate these lessons into exercises that teach the concepts at a pace children can comprehend. The notes could be developed by teachers or supervisors under supervision. 
This minimal model allows a basic standard of student learning to occur with only small amounts of training for even the most poorly qualified and inexperienced teachers. The collection of student learning results - as the minimum supervision required - ensures that the package overall is proving effective. A section below describes the channels through which a package like this might be delivered to clients, and a later section details the capacities a local NGO would need to deliver the packages cost-effectively. The sections on quality and relevance describe how this approach under appropriate circumstances might be elaborated to ensure better results.

\section{Access: Supplementary materials}

Because schooling has been interrupted for many Afghan children, or was not previously available to them, the children now attending classes are of varying ages and skill levels. In some home schools, when children complete three years they continue to repeat previous grades just so they can stay in school. Many of these informal schools cannot provide the subject-specialists required for the 7 subject syllabus in grades 4-6. Classes often comprise many children, which makes it difficult for the teacher to provide any individual attention. Finally, seatwork normally involves copying from a blackboard and children do not have an opportunity to test their skills independently. A number of these problems might be addressed through supplementary materials (which are unlikely to require approval of the authorities if pictures are chosen carefully): Some of the specific options are instructional boxes or self-instruction aids.

\section{a. Supplementary materials - Instructional boxes}

The "boxes" would contain 100 or more math, reading or science cards (like an oversize card file) with short reading paragraphs or math problems on one side, and comprehension questions (and answers) on the other. The cards are identified with colored tape at the top as "easy", "average", "more difficult". Children must read them in order from easy to difficult and answer questions in their notebooks or on slates. Older children in a class would be able to move quickly through the boxes and it would allow those with advanced skills to further their education. All children would benefit from learning independently (little independent learning goes on in Afghan schools at present).

If used judiciously the cards can enrich a poor curriculum and make up for deficiencies in an existing program. For example, science which is now missing from the grade 1 to 3 syllabus, could be part of the reading practice cards (being careful about the selection of pictures and materials), and material from grades 4-6 textbooks could be used to build the skills of grade 3 graduates who cannot find a teacher to teach these grades. ${ }^{4}$

The cards are best developed by teachers who are conscious of the reading levels of students. The technical supervisor should help them develop the framework for the content (length and format for the reading passage and questions), selection of topics and skills being presented, appropriate comprehension (as opposed to factual) questions, and reference materials upon which to base the content. The "boxes" are not costly to mass produce and can be provided to schools and classrooms as needed.

\section{b. Supplementary materials - Self-instruction aids}

Modular self-instructional materials based on the grades 4-6 curriculum are required for use where teachers are not qualified to teach these subjects, or where teachers are not available at all. Again these help older and more advanced students to work on their own or become part of a multi-grade class and work at their own grade level. The packages should be prepared in a way that makes them suitable for differences of local scheduling of schools, the kinds of facilitators that use them, and the circumstances in which they will be used. The providers and field workers should develop the specifications for the packages, building on what currently exists, as well as on international experiences with these kinds of programs. (A number of international programs use self-instructional materials, many based on the old IMPACT system started first in the Philippines and now also used in Bangladesh and other countries.)

4 UNESCO has developed math and language books that compress grades 4 and 5 content, and which might be suitable for grade 3 graduates who want to continue their education. 


\section{Access: Flexible, alternative delivery systems}

Delivery of education programs has become a serious concern of members of the assistance community because of difficulties in the Afghan political situation. Many would concede, however, that there is still room to work within a "principled" framework, both to support informal schools in urban areas and in rural schools where communities have taken initiatives to establish their own programs. It is likely that difficulties in the form of closed schools, resistance to foreign influence, tightening assistance budgets, etc., will continue to affect the delivery of education services for some time to come, and may at times intensify. While some agencies may find it possible to work openly under these conditions because of their well-established local presence, others will probably want to lower their profile. Several opportunities exist to provide educational services in ways that are less costly and require less foreign presence than the methods of delivery now being used.

An important point is that a number of the present concerns arise as a consequence of supply-driven models, where the assistance agency "chooses" the targets of their assistance, the places in which the delivery will take place, and in some cases the agents who will deliver it. When the assistance agency determines the contexts and targets - cities, regions of the country, or specific groups - several things happen. First, the assistance agency must ensure that the characteristics of the groups, contexts, and agents are appropriate. This consumes resources and effort, and means the assistance agency assumes a regulatory role. Second, if the targeted group has not been instrumental in choosing the service, it may also feel more lukewarm about it; its negotiating position is strengthened and it can hold out for advantages if it allows itself to become included in the targeted group. Efforts to put the program on a sustainable basis may elicit similar demands, and it becomes difficult for the assistance agency to withdraw support.

Some feel these disadvantages are outweighed by the advantages of supply-driven approaches, including the fact that agencies can target groups who are thought to be the most deserving of the services by criteria determined in a climate of limited resources. ${ }^{5}$ In the Afghan context, however, with its low participation rates and limited education opportunities, it is difficult to identify which children are disadvantaged. In effect, all out-of-school children are disadvantaged if their reason for being out of school is lack of opportunities.

In a demand-driven model, on the other hand, where assistance agencies offer a variety of effective program packages, and self-selected clients can choose what their needs, more of the emphasis is placed on clients' needs, and less on "policing" the agents or targets of delivery. Though still raising the issue of equitable distribution, demand-driven models shift development concerns to the more technical ones of quality and efficiency in supporting the demand. The demand-driven model, of course, raises the same problem seen in the Kenya example above: since the program recipients are self $f_{\bar{z}}$ selected, there may be èquity questions in who eventually receives services if resources are limited. However, there are also equity issues raised when assistance agencies target specific groups of disadvantaged leaving few resources for óthér groups, or even for those willing to pay. Groups that come seeking services are much more likely to pay some if not all of the costs.

Despite the obvious advantages of a demand-driven approach, this paper reviews delivery models from the more conventional, supply-driven approach used mainly by the assistance community. The discussion is approached from the perspective of technical inputs and considerations that are important in the use of different models as means of delivery.

\section{a. Alternative delivery - Home-based initiatives}

Since the crisis over girls' education developed, home-school initiatives have grown rapidly in urban and rural areas. The schools consist of anywhere from one to six classes, and may occupy a room in a person's house or an empty building or what was previously a formal school. Some have morning and afternoon shifts. In Kabul the schools often consist of several classes with many enrolling boys in the lower grades. Some boys attend 5 Interestingly, one evaluation of a project noted the importance of enrolling daughters of influentials so that a norm of educating girls would be
established for the rest of the community. The report did not necessarily recommend this criterion but it does show the difficulties of choosing the targets for assistance. 
both home-schools and formal schools because their parents feel the formal system has deteriorated to such an extent that little learning goes on. ${ }^{6}$-In addition to a small number of home-schools, some parents resort to hiring tutors for their children. However, many parents cannot afford this more costly arrangement.

A number of issues have arisen with regard to home-schools that make it difficult for the assistance community to agree about whether or how they should be supported. These issues include whether the schools should be considered a temporary option and thus supported fully as an "emergency" measure; whether they should be seen as a long-term option and made self-sustaining; whether they create an inferior alternative or parallel system to the formal system and should therefore be discouraged as inequitable to girls; and whether the quality or length of schooling is equivalent to that in the formal schools.

Though home-schools are viewed by many in the assistance community as an interim solution, there is reason to believe that home-schools may be around for some time in Afghanistan. One reason is that they provide opportunities for children whose parents would not otherwise allow them to go to formal schools (even if open to them), especially younger children and girls. It is doubtful that future Afghan governments will be able to support universal education, even in the best of circumstances, and therefore home-schools, or schools like them, may be the only education option available to many Afghan children. In many countries of the world, assistance agencies support schooling that respects the special needs of educationally disadvantàged children. Home-schooling is a common way that these needs are met.

The rise of home-schools is seen by some as an opportunity to experiment with cost-effective and efficient modes of delivering education that may be useful over the long run in serving many rural and urban Afghan children. They remove the need for costly building construction through the community's contribution of a shelter, and since parents have a closer relationship to teachers, there may be more accountability for learning outcomes. If the other elements of quality - materials, good teachers, writing supplies, and supervision - are present and combined in a way that promotes successful learning, this kind of education can prove highly effective.

It should not be assumed that the quality of education in home-based schooling is any less effective than formal schooling. Considerable evidence suggests, to the contrary, that many home-schools provide a better education in the grades available. Many of the teấchers who teach ịn these schools have had previous experience in the formal system. And many find it convenient and more motivating to teach in the environment of a nearby neighborhood school. Overall, the quality of instruction in home-schools probably varies considerably depending on the abilities of teachers. A more consistent quality could be obtained with the kinds of support offered in the next sections on "quality".

The additional concern has been that some home-based schools only reach Grade 3, and fherefore do not provide a full primary education. The Taliban reportedly ban girls from continuing beyond Grade 3 , or roughly from nine years of age. Some home-schools use this ban to discontinue classes after Grade 3. Others continue classes to the end of primary or re-enroll girls in the third year so they do not need to leave school. It is quite possible that many home-schools stop at this point for other reasons, including the important one that the syllabus increases from 3 to 7 subjects at Grade 4, and therefore requires more qualified teachers.

Concern about the length of schooling in the home-schools is a reason not so much to deny the need for these institutions as to consider technical ways to overcome the obstacles. For example, the delivery of grades 4 through 6 can be accomplished by preparing home-schooled children to enter the formal system (assuming by then that the principle of equal rights to opportunities was not preventing entry into these higher levels), through self-instruction, roving teachers or other delivery modes. These alternative modes should also not, as in the case of home-schools, be assumed inferior until proven so by comparing the learning outcom students using different systems of delivery. The lack of upper grades in many home-schools can be more a failure in the means available to deliver education programs than in the type of school itself. ${ }^{7}$

6 Many teachers do not show up for class in the formal system, because their salaries are not paid or are paid sporadically, and few materials are available unless paid for by parents. Many of the teachers were also women who are no longer allowed to work.

7 Girls who leave home-schools after grade 3 may not, in any case, have been allowed to continue in formal schools if those had been available. 
To answer questions about home-schools requires a study before one can be sure equity principles are being violated. The policy issues are to important to leave to uninformed opinion. There appear to be no obvious reasons why human rights principles cannot be accommodated through home-school delivery. The criticism that these schools provide only modestly for the massive need for services in Afghanistan reinforces the conclusion that the problem is more the inadequacy of delivery than the particular location where schooling takes place.

Developing a clear policy on support for education is difficult given the various realities on the ground in Afghanistan. Though on the one hand, a principled approach would seem clearly to preclude support for the formal system, there are many areas of the country where formal schools continue to enroll girls and boys. In others under strong Taliban control, girls may be excluded from the formal system. There, while boys continue to have the "privilege" of continuing in largely defunct formal schools, girls may be attending more effective home-schools. The authorities provide little support for either kind of school and therefore the question is not even discriminatory use of resources. Does this mean support should be denied to communityinitiated schools simply because some in urban areas were started as a response to Taliban edicts?

\section{b. Alternative delivery - Community-based initiatives (CBI)}

Community-schools and home-schools are not always easy to distinguish. Home-schools are generally thought of as a phenomenon of urban areas but many so-called home-schools are also found in rural areas. Community-schools tend to be larger and a product of an entire community seffort, not like schools in Taliban controlled urban areas that must be small, comparatively invisible, and cater to children in the immediate neighborhood. Home-schools are more suitable in these conditions.

Rural schools of several grades occupying larger, more formal quarters" are usually called community-schools. They tend to face some of the problems of education in rural areas, namely an historic lack of accessible opportunities for both boys and girls, an almost non-existent enrollment of girls, and little traditional support for education. However, the experience of living in the diaspora has convinced many that education is important for the future of their children. Groups such as SCA, NAC and local NGOs such as AG-BasEd and ADA report that many of their new education initiatives are demand-driven ${ }^{8}$ - that is communities come asking for education services.

Community-based initiatives offer the advantage of being able to support more variable forms of education delivery (formal schools, full program non-formal schools, and informal home-schools), as well as shaping the conditions of schooling to meet specific local.needs for scheduling, location and staff. In addition, they may be able to attract broad-based community support for fuping, in-kind resources, and resolving difficulties in the provision of services. In many cases communities provide on-site management and monitoring help that can make a difference in the quality of the education services. As is the case of homeschools in urban areas, the advent of community based initiatives has been an opportunity to provide more flexibility in services.

Several organizations have consciously worked to involve communities in support of education programs. Some have expressed the view that mobilizing community participation has been difficult and not entirely successful. Generally the problem has been that communities have not contributed significantly to the maintenance of the school, the payment of teacher salaries, or the provision of other material needs of the program that would sustain it over time. Where this has been true, implementors describe the problem as one of limitations of resources, experience, and technical capacity that prevents community members from participating fully.

8 This is not the kind of fully demand-driven model described earlier in which the implementer is largely unconcerned with where or who will carry out the model other than to provide minimal support in how to implement it. By contrast, in this other model, the assistance agency determines whether the community demanding the service fits the criteria for participation, and usually expends considerable effort in ensuring an appropriate environment and adequacy of supplies. 
Members of Afghan NGOs working inside Afghanistan report that they have had a better experience in involving communities, and while admitting to early difficulties and false starts, feel that eventually after developing the trust of community partners, a great deal of support can be attracted. Some argue that synergies can occur when the needs of communities are addressed comprehensively. For example, one NGO reported that when they helped repair a war-destroyed irrigation canal in one community, agricultural production rose, which, in turn, permitted parents to contribute to the support of the school.

This example echoes examples found internationally, that when communities are involved in their own comprehensive development, effects are more likely to be sustained. This fact has two important implications for the involvement of communities: one is that the institutional models created to support schools may also become the models that carry over to other sectors in the society, and therefore must be established with care. In general, the institutional arrangements to be based on social arrangements Afghans plan to use to develop other aspects of their society. ${ }^{9}$ Though this should be something Afghans decide, one of the issues is whether the arrangements should be based on the traditional tribal model with people in designated positions relating to one another in prescribed ways, or a more broadly based and participatory model that solicits opinions from all those who have an eventual stake in the outcomes. Community involvement in education decisions can play an important part in establishing these processes.

The second implication is that building sustainable structures takes time. A community may not consider education a priority until their basic needs are met, including such economic and psychological needs as adequate infrastructure. If these are the conditions under which communities can effectively participate in education programs then funders may have to reconsider the time frames within which they ask agencies to work. Resistance to education programs is not always a consequerace of discriminatory practice - it can also be a matter of perceived priority.

\section{c. Alternative delivery - Lessons learned regarding community participation}

Experience from other countries suggests that, as has been the limited experience in some Afghan education projects, community participation has not always produced the results expected, whether because the strategy to involve communities was flawed, or because developers' expectations were unrealistic. If community participation is to become a delivery strategy for education, as conditions inside Afghanistan suggest must be the case in the short and long-term, it must be designed carefully to provide the most effect. One major failing in international experience has been that developers have tended to "tell" and "sell" communities what they were expected to do, and frequetly did not give them enough "space" to take initiatives on their own. Experience shows that it is important to consider how communities are involved.

Project funds in international experience have also tended to support community involvement largely as an upfront activity that is expected to take off on its own after suitable discussions and arrangements have been made. Many designers do not look sufficiently into the time required to nurture institutions such as Village Education Committees, School Management Committees, Parent Teacher Associations, etc., that are formed to support the long-term interests of their schools. This may require developing in these organizations capacity to serve the more diverse needs of local people so they will see them as institutions worth supporting. One way of doing this beyond the obvious skill-development areas of management and fiscal responsibility - is to encourage school committees to become reference points for other technical and life skill programs desired by the community.

Community participation in support of schools in other countries has been most effective in circumstances where parents express a strong demand for education, but for reasons of various kinds governing authorities have either not been able to provide sufficient opportunities or have not provided them effectively. The reason is often that areas are remote and government officials are not able to supervise even the few schools that exist on a regular basis. The situation in Afghanistan, though constrained by a unique set of circumstances, nevertheless has certain characteristics in common with this condition. Demand for education services is increasing and sufficient opportunities are not available, or when available are not effectively delivered.

9 One community complained that an assistance agency directly implementing a project held endless community meetings before donating a small 
Another condition where community participation has proved effective is under circumstances where parents are reluctant to send all or some of their children to school. When they are included in the process of determining the conditions of schooling such as school location, teachers, scheduling, and monitoring of student and teacher attendance, they are more likely to feel secure about sending their children. Again these circumstances appear applicable to Afghanistan.

The reasons for involving communities are complex. Community participation can be used as a strategy to augment resources, to encourage the enrollment of hard-to-reach groups, to extend the government's oversight over schools, or to promote the practice of a civil society where communities take more responsibility for their own development. Each of these purposes requires a different approach to community involvement. If expectations are clear from the start, it is apparent when progress is being made or when the process for involving communities needs to be modified. Motivating communities to support their schools, for example, may not necessarily result in more material resources to run them, especially if communities are poor. $A$ narrow involvement of the community in providing resources can after a time cause them to become disinterested in supporting the local school.

Projects which incorporate community participation as a major strategy in delivering education programs need a clear view of what it is they are trying to encourage. They also need a well defined process whereby all the involved actors - community, NGO, assistance agency, government officials - understand the part each is to play. One of the more successful examples of this kind of process is found in the Community Support Project in Balochistan where an NGO facilitates agreements between the government and the community, and guarantees that each complies with its side of the bargain. The 14-step process used by this NGO is designed sensitively to address the needs of a tribal society with hesitancies about working with the central government, and where tensions between factions in the community often threaten the sustainability of institutions. The process consists of a series of transparent, accountable steps so that each side gains confidence in the other.

To summarize some lessons learned internationally about community participation:

- $\quad$ The purposes of community participation need to be clear from the start, so it is apparent when progress is being made and when corrective actions are required.

- The role of initiators is a sensitive one, especially when the initiator is an outsider to the village and, even more so, when the outsider is a foreigner. Outsiders, however, can play the useful role of connecting relatively powerless communities to external sources of funding and expertise that may help solve education problems.

- The extent to which community participation is seen as effective is directly related to the expectations for it. Community participation may have little instrumental value where techniçal aspects of education quality are of concern, where public delivery of education is reasonably effective and efficient, or where demand for education is well established. However, when expansion of opportunities is the main objective, winning over and involving communities often proves an effective strategy.

- The expectation that communities can be counted on to contribute significant resources of time, effort and money is often a miscalculation, especially if the community members are themselves impoverished. Expecting communities to provide significant support may restrict the kinds of groups that can be served.

- Community participation can be costly. Projects tend to "front load" their investments in community participation with discussion meetings, surveys, and initiation activities to establish school programs, and then expect communities to take over and continue to support the programs. In most cases projects must continue to fund certain aspects of community involvement to ensure sustainable local institutions. 


\section{d. Alternative delivery - NGO delivery}

Other countries have found NGOs to be useful vehicles for delivering education programs, especially when programs are brought to scale. Use of NGOs makes sense in situations where government capacity is limited or disinterested, and where NGOs have an established record in providing community development support. The international assistance community may not have the capability nor the mandate to work in rural and remote areas, and therefore needs to find facilitators who can link these communities with the sources of education inputs. When conditions are appropriate, NGOs can cost-effectively manage and deliver education services in an interim period until such time as an efficient government system is in place. ${ }^{10}$

The advantage of using local NGOs as a conduit for education delivery is that they often:

- $\quad$ may be able to approach communities more sensitively

- may have experience in community development (and developed trust in specific communities)

- $\quad$ allow foreigners to maintain a low, less confrontational profile

- can more effectively translate the needs of communities and aid agencies to one another

- can ensure that services are sustained

- $\quad$ can be more cost-effective.

Complaints have been raised by some Afghan NGOs that the assistance community has been more interested in acquiring their services than in helping them develop capacity or take advantage of new opportunities that arise to advance education objectives. Some have difficulty in sustaining long-term staff and developing their own capabilities within the meager overheads they attract. To work effectively they may need to build longterm relationships in communities through other projects, with the consequence that the time-frames and contracts for delivering specific services may not be realistic or fully cover their efforts. International assistance agencies, on their side, report that they often have difficulty finding reliable local NGO partners. Many have a reluctance to lose control of their projects for fear they will not be implemented properly. One of the necessary steps in sustainable development, however, is to turn over the process and products of what should have been joint efforts to local organizations, and therefore, even when there are difficulties involved, the assistance community should be working toward supporting local organizations that have a good track record.

A later section looks at how local NGOs might be strengthened to take on a larger role in the delivery of education services.

\section{e. Alternative delivery - Other delivery óptions}

A number of alternative delivery options for education services have been used in other countries. Here we will only mention a few. Since none has been implemented in Afghanistan in any but a small way, each would need to be studied further to ensure that it would be an effective option.

- Interactive radio. There has been considerable experience in teaching math, science and foreign languages by radio in a number of countries of the world with confirmed positive results in student learning. For primary school settings each subject program is usually broadcast one-half hour a day. The teacher is provided a guide in her/his own language, and the children spend about 10 minutes a day completing workbook exercises. An advantage of radio learning is that a teacher who may be minimally qualified or who has difficulty in the subject matter, can provide the necessary facilitation while at the same time learning the subject content herself/himself. In addition, the radio lesson models a more interactive learning method that the children usually enjoy. As a national system such programs often cost less than conventional programs while maintaining standards of quality across their audiences.

10 In countries where a government bureaucracy exists but is ineffectual in education delivery, NGOs have played a pivotal role in on-the-job training of staff. 
There are several reasons this approach might prove useful in Afghanistan. First, with some technical supervision related to edutation content, capacity will be developed in $\mathrm{BBC} \mathrm{REACH}$ to produce programs like these. Second, radio broadcast capacity to beam programs into Afghanistan exists. Third, in areas where teachers are not available or do not have satisfactory skill levels in the subject content, quality teaching might still be provided through the medium of radio.

Self-instruction. The materials needed for self-instruction have been described above. Besides serving as a useful teaching device to reinforce concepts and skills, they make it possible to deliver education in a number of convenient ways - in multi-graded and varying ability classes, where teachers are not available, or where schooling is interrupted for a time. They are appropriate in urban settings where for political reasons it is difficult for children and teachers to come together, and in rural settings where teachers have difficulty with the subject matter at higher grades.

- Roving teachers. Some countries use roving teachers as either a cost-cutting device or to reach inaccessible groups. One teacher can cover a number of classes. Although these teachers can be used at any grade level, they are most effective at upper levels of the primary and secondary stages in conjunction with self-instructional materials. The teachers visit children periodically - at intervals of a week or more to check children's work, present new concepts, and assign future work. Other roving teachers include "barefoot" teachers or "nomadic" teachers who go where they are needed, or even move with their clients.

- Mosque schools. Mosques have been used as a venue for "modern" subjects, either in conjunction with Quranic schools or as self-standing schools. Sometimes Mullahs are trained, or a qualified primary teacher is added to teach language and mathematics. There have been advantages and disadvantages in these schools, the advantages being that the "modern" subjects are introduced into an already functioning madrasa with established sources of support, and an acceptance usually that boys and girls will study together. The disadvantage is that instructional time is limited by the other uses for the mosque, and the longer time usually spent in religious studies.

\section{f. Alternative delivery - Summary}

The concern of the assistance community over questions of accessi and delivery is important. While many policy questions are yet to be resolved, and may in the end constrain what is possible, technically the answers are more likely to come from efficiencies in the way education is delivered. This section has described three ways in which more opportunities might be made available at less expense in the various settings of Afghan education:

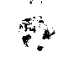

- Through the efficiencies of self-evident simple "packaged programs" for the primary years that include the essential elements of quality instruction

- Through supplementary material packages that fill in the gaps arising from the ad hoc delivery systems currently in effect

- $\quad$ Through the efficiencies of alternative delivery systems that channel programs to broader audiences at less cost.

Although donors may not yet be ready for completely demand-driven assistance that provides services regardless of the characteristics of recipients, nevertheless efficiencies can be made in the current modes of delivery that open opportunities to an expanded audience. Up-front design attention to efficiencies of delivery in the end will allow the same levels of assistance to reach a broader audience. The danger in the Afghan situation is that the arguments and counter-arguments about the appropriateness of various schooling venues and delivery systems may lead to "donor-fatigue" and in the end to a stalemate where little is accomplished. 


\section{Access: "Action" research to scale up opportunities.}

Experience in other countries ${ }^{11}$ has shown that scaling up pilot programs often dilutes the quality of the education offered, even when the model has been tested and appears successful on a small scale. It would be appropriate in the context of Afghanistan to fund an experiment in massification to determine the most cost-effective approaches to scaling up education opportunities. The focus of the activity should be rural areas where the conditions of distance, less qualified teachers, and the difficulty of supervision make it important to determine the best ways to provide opportunities. Community demand in these areas appears reasonably high, and considerable support has been forthcoming from local authorities in helping Afghan and international NGOs establish classes at the primary level.

It would be useful in such conditions to make a comparison of the results of scaling up using two or more delivery systems. For example, an NGO with experience delivering an established instructional model could be asked to establish a specified number of schools in a clearly defined area and within a specified time frame. The same NGO would be asked to train a local entity to establish a similar number of schools in the same area and timeframe. The second year a larger number of additional schools would be established by the NGO and the local entity. The results would be compared in terms of student learning, support efforts, and costs, and would inform direction for future investment. In addition, if the NGO proves to be an effective training agent, it might eventually take on the specialized role of supporting local provincial and regional groups in establishing their own schools.

Conditions appear favorable for this type of action research in several provinces. Other action research with policy implications might include:

- A comparison of student learning in classes where only instructional materials are provided, and in classes where the same materials are supported with training and supervision

- Comparisons of learning outcomes in students of teachers who remain untrained, and those who receive various types of trainings (trying to keep all other factors fairly equal)

- A comparison of learning outcomes of students in home-school programs at grades three and six, with those in formal schools in the same grades.

\section{Quality of programs}

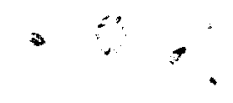

\section{Issues of quality}

\section{a. Quality - Approaches}

Although program quality appears an elusive goal, a great deal is now known about how to make quality improvements. Some of the main points are that:

- $\quad$ approaching education programs systemically is usually the best way to improve quality (that is, a program must be seen as a whole, with attention given to the effective interaction of all its components)

agreed-upon aims help to focus all parts of the system *

- continuous monitoring of outcomes makes it possible to see whether the aims of the system have been met

- variations in outcomes demonstrate where weaknesses and strengths of the system lie, and make it possible to take corrective actions

- instructional materials (or national curricula) are a good entry point into the reform of a system training, supervision, and assessment supports can all be tied directly to materials.

From these points it follows that all components must effectively reinforce improvements in outcomes, and that even one weak component can cause quality to decline. Instructional materials are the core for they allow curricula (objectives of the system) to be translated more consistently across schools.

$\overline{11 \text { BRAC (Bangladesh) and Escuela Nueva (Colombia) are the most notable examples. }}$ 


\section{b. Quality - Problems}

There are a number of basic concerns relating to quality in the Afghan context that can be summed up as follows:

- instructional materials vary in quality — the most commonly used are an obstacle to student learning ' while others teach children even when teachers are weak

- $\quad$ some teacher notes are complicated and written to the level of highly qualified teachers rather than to those less well qualified teachers working in many schools

- $\quad$ some materials force the teacher to use rote learning by being too difficult and too compressed for the children's levels

- training for the most part is vintage, some being imitations of discredited programs in other countries - little of the training addresses the practical needs of teachers and no effort is made to test its effects on student learning

- $\quad$ supervisors focus on teaching behaviors which are often not appropriate ways to help children learn

- little attention is paid to learning outcomes, and when it is, information is collected in a way that is not useful in improving program quality

- almost no mechanisms exist that involve teachers, supervisors, program developers, and others in reflecting on what they do.

\section{c. Quality - Discussion}

Some field providers and consumers of education services whom we met identified poor program quality as the main issue facing the sector at the present time. Complaints ranged from the content of the materials to the difficulties teachers have in implementing the approaches they are taught. Some blame the poor results on unqualified teachers, others on the inadequacies of the training which may be too theoretical and too far removed from the models of teaching/learning known to the teacher. The solution offered is often more teacher training in the belief that more training will be better. The logic is obviously flawed. More of what did not work the first time is unlikely to work the second time. This is not to say that training is not important, but rather that it needs to be "fixed" (ensure results) before it is spread further.

For a number of years, the international conmunity has been encouraging student-centered approaches to classroom learning. These methods of learning are undeniably good in certain contexts. However, recent research is now looking less favorably on unstructured, group-oriented, or fully individualized forms of learning. These methods work for certain children, in learning such creative subjects as art or poetry and when directed by highly competent teachers. But they arè often not as effective in average classrooms with normal children and for subjects which require a certain amount of repettitious practice. Children learn by different means, and teacher-directed approaches used in many schools in Afghanistan can be highly effective as long as they include problem-solving and analytical exercises that stretch the thinking powers of children.

Student-centered approaches are difficult for Afghan teachers to manage with large numbers of children in the cramped conditions of many schools. Research in Pakistan, in schools not unlike those in Afghanistin, has shown that the teachers who produce the highest achievement in their students were ones who used a systematic approach that incorporated practice of the skill or subject matter through a variety of reinforcing tasks - questioning, repetition, problem-solving, etc. - under the guidance of a teacher, and then through independently completing problems with feedback from the teacher both in school and through homework.

A second problem of quality that is largely overlooked by education providers to Afghans is the issue of how to measure quality, and at the same to know when or if improvements are occurring in the education program. On the one hand, almost every Afghan program measures access results through a number of indicators: enrollments, schools, teachers, etc.. But few systematically collect data on quality outcomes, and those that do rarely use the results effectively to improve the quality of their programs. These quality outcomes can be defined in a number of ways, but in general the most successful are ones related in some way to student 
learning outcomes however these are defined. Some educators object to using achievement scores as the main indicator of a program's outcomerbecause they feel there may be other outcomes related to children's behaviors that are also important. They argue that depending too heavily on exam scores can produce an exam-driven system that fosters competitiveness in children and teachers. Be that as it may, a system which is trying to improve its academic performance has little choice other than to use some form of achievement scores to measure its success.

\section{Assessing curriculum models and instructional materials}

Research has shown that good curriculum and instructional materials are the core elements around which a quality program can be built. Schools having no textbooks or other instructional materials can raise learning outcomes many times by acquiring and using materials. For this reason it is clear that instructional materials of any reasonable kind are probably better than nothing.

Given the resources invested in education services in Afghanistan, however, the assistance community should be asking whether the currently available instructional materials are the best that can be provided to Afghan children. ${ }^{12}$ Good models may be available, but given the nature of the complaints that are raised in interviews and evaluation documents, it would seem wise to submit the existing instructional materials to an independent assessment by a competent expert to determine what if any changes need to be made to improve their effectiveness.

The argument for addressing the question sooner rather than later is that agencies need to know the strengths and weaknesses of the materials they are using, and agencies that develop the models should be concerned with making them as effective as possible, as soon as possible. Numerous school children will benefit immediately from these improvements, and many children in the last decade could have had a better education if this had been done earlier. ${ }^{13}$

The weaker argument for waiting is that, until an authority exists inside Afghanistan to deal with questions of a national curriculum, it may be premature to improve or create new models that may not be accepted by the authorities. The weakness in this argument is that the present political situation inside Afghanistan shows little sign of changing in the near future, and even if it,did, there is still a likelihood that demand would exist for alternative curriculum models to those created by the authorities. Internationally, curricula revision and modification in best practice is a continuous process. If Afghans are supported in this effort and learn up-todate skills, they will be able to apply them if and when conditions change. In the meantime they can continue the process of improving existing models.

\section{At present, curricula are being chosen for delivery by the assistance community for non-educational} reasons. Although this may be partially excusable in terms of the political complexities of the situation in Afghan education and the lack of education expertise in most of the assistance agencies, it is not an educationally sound way to operate, or one that funding agencies should want to support if they aim at providing quality education. Most Afghan children do not now seem to be using the best of those materials available.

To assess existing models requires a series of steps similar to what has been described in more detail above for assessing the delivery capacities of models (the two could be carried out simultaneously). The aim would be to identify where existing models are in need of support, and what sorts of strengthening elements might be used to focus instruction and improve the measurement of program effectiveness. The steps include:

- $\quad$ agreement by assistance providers that this is a useful step

- determining criteria to be used in assessing the models

- the actual assessment which identifies strengths and weaknesses, and recommends specific corrections

- commitment and support to make the changes, assigning responsibility for the changes, and seeing that they are accomplished, field-tested and implemented.

12 In other sectors there does not seem to be the same lack of concern over the product that is being delivered. Would a leaky pump be provided, a medicine which disables the patient, a road that immediately disintegrates? That, in effect, is the equivalent of what is happening in education because so little is invested in the development of effective programs.

13 An assessment of USAID assistance to Afghanistan written in 1994 makes many of the points that are made here. 


\section{Immediate options for improving models}

The previous section made a suggestion for improving the quality of the core sets of available instructional materials. ${ }^{14}$ There are also immediate actions that could be taken to support and improve existing programs. These are simple, cost little, and will almost certainly improve student learning outcomes (but should be tested for their effect).

To make major improvements in education results requires systemic approaches. Little impact, for example, is likely to result from perfecting any one aspect of an education program without considering its relationship to and improving other parts. The options recommended below address different weakness in the present education program. Therefore, although solving one problem will help, it will not help as much as correcting a number of them.

\section{The options that are most likely to strengthen existing program models include a focusing mechanism, more practically-oriented teacher training, teacher supports, an overhaul of supervision, assessment of and emphasis upon student learning outcomes, and mechanisms for reflection.}

- A focusing mechanism. In some countries, departments of education publish small booklets of specific objectives (derived from national curtie ulum objeçtives) divided by groups into what a child should learn in each subject matter at each grade level of the primary system. These booklets are called in at least one casẽ "Minimum Levels of Learning" (MLL). The educationnists have agreed that schooling programs will produce these competencies in children by the end of each school year, and that they will test children to determine whether they have succeeded. MLL sets the focus for all inputs to the system. Teachers study MLL in training and know they are expected to help children achieve them.

Instructional materials are developed that break down the MLL competencies into specific skills that children learn lesson by lesson until they achieve them. Supervisors know they must look for MLL competencies when they observe teachers teaching, and tests are specifically developed to measure the extent to which children learn each competency. MLL, thus, focuses the components of the education system to produce specified learning outcomes.

Some of the Afghan educationists know where the original objectives for the education system exist (used by UNO materials). These could be simplified and published to make clear what is expected in terms of learning outcomes from each model. Beyond that, it is an effective way of making it possible to focus each component of the education program on the same learning outcomes. Trainers, teachers, and supervisors would then have a clear mandate for what they are trying to produce.

- Improvements in teacher training. A superficial look at some of the training programs suggests they are too theoretical, and filled with superfluous information and techniques that it is difficult for teachers to implement. No program we are aware of in the Afghan context actually assesses the effects of the training on student learning, which leaves programs in danger of being largely irrelevant to the process of learning. It is, for example, irrelevant whether teachers use specific methods or prepare lesson plans (these are not the ends expected of an education system) if student learning does not improve as a result. It cannot be assumed in the Afghan context that techniques developed elsewhere (or long ago) will still ensure learning results.

Many countries have discovered the advantages of short practical trainings of one or two days in intervals of a month or more throughout the school year. The training is "practically driven", that is, it first addresses those aspects of instruction the teacher needs to be effective $æ$ such as the use of lesson plans in teacher guides, subject content training, ${ }^{15}$ classroom management techniques and discipline. Only later, as teachers become more confident in their ability to cope practically in their classrooms, does it test more theoretical subjects such as child development and higher order thinking skills.

14 The same process could be undertaken for out-of-school, secondary, tertiary, literacy, non-formal, vocational, etc., whenever a set of core materials exists to teach these courses.

15 One skill that teachers were having difficulty with is phonetic approaches to reading. They continued to ask children to spell and then pronounce a word rather than sounding it out. The teachers who weresuccessful at using phonetics usually produced more confident learners who were not afraid of trying new words when asked. This skill appears to contribute so significantly to learning to read that it needs to be learned by teachers. 

follows them can produce the learning results desired, and if constructed in a careful way they can remove some of the problems of inadequate teacher content knowledge, inability to translate new methods into classroom practice, and lack of student practice exercises in higher order thinking skills. - Furthermore, if designed in a basic format that is repeated lesson by lesson, training can be costeffectively reduced to learning the lesson-plan pattern in the guide. After a period of practice the teacher learns new methods of instruction in a concrete as opposed to theoretical way. The guides work well for inexperienced teachers but do not need to constrain the better, more experienced teacher. The guides, of course, must be tested to ensure their usability and effectiveness in increasing student learning.

There are three important caveats in the use of guides. First, teachers will not use guides unless they are extremely simple and have as few written words as possible. Second, they need to practice using them under the guidance of a trainer until they feel comfortable with them. Teachers should feel it is easier to teach with than without them. Third, teachers must expect regular visits from a supervisor who will test student learning. If the results are good, the supervisor should not observe the teacher further (whatever she/he is doing is right). If they are poor, the supervisor must determine what the problem is (attendance, lack of books, teacher adherence to the suggested steps in the guides, etc.). Since the teaching steps will have been tested to be effective in student learning, the guides can be mandated for weak teachers until such time as they increase their skills enough to produce satisfactory student learning.

- "Model elaborations" of lessons. Another modest option to improve learning would be the elaboration of lessons in grades one and possibly two. In order to cut costs, some existing textbooks jam too much learning into too few pages, and teachers follow the pages religiously, often equating a page with a day's lesson. Young children cannot learn to count from 1-10 in one lesson with understanding, nor can they learn to recognize alphabet letters and words incorporating them simultaneously at the very start of reading. They cannot leap from this kind of learning to paragraphs of writing. Some of the difficulties teachers face are due to the difficulty of materials that do not systematically relate skill development to children's learning capacities.

Under the supervision of a person tho tinderstands these issues, teachers and supervisors could develop models for teaching each number añd each alphabet letter lesson, and then provide the transition practices that lead from these building blocks of learning to their more complicated use in solving problems and reading paragraphs. The work involved is not long and engages teachers and supervisors in a productive dialogue about'what works to improve learning. They would of course test their materials in simple ways to ensure that children better or to determine whether they have to improve the model lessons further. The advantage is that learning in grade one (which often has the highest drop-out rates) would be improved and made less daunting for children.

- Instructional aids. Many of the agencies involved in education delivery have produced learning aids, such as number and alphabet friezes, and other low cost methods to make learning more concrete. Many are quite good and should be shared with others. ACBAR could do an exhibition of these, so agencies could learn from one another rather than spending time reinventing what already exists. Ideal would be explanations by their developers about relevant grade levels for which they were designed, how they should be used, and what learning results they are intended to improve.

Supervision. The methods of supervision in many classes create an atmosphere of anxiety among teachers, making it difficult for them to develop a sense of professionalism. Worse, they no longer rely on their own abilities to think through problems and adjust to the conditions of their classropms. They cling to behaviors they know supervisors are looking for, and when these do not work they fall back on memorization and rote learning as convenient ways to get through lessons that are too difficult for children. "Wrong" patterns are so wide-spread that it is obvious they have been taught to teachers and 
reinforced as the "right" way by supervisors. Research has found little link between specific teaching behaviors and student learning outcomes, and therefore trying to ensure specific teacher behaviors is a waste of time and resources.

For whatever reasons, teachers pass their anxieties on to the children by not trusting them to do school work on their own without coaching from the teacher. A child who goes to the blackboard has each word sounded out for her/him, or even spelt. No new phrase or problem is given to a student before being modeled by a teacher. Teachers see this process as what good teachers do, and because supervisors reinforce this behavior, children never develop into self-confident learners.

This process needs to be reversed, and a start can be made by a change in the methods used by supervisors. If supervisors make clear that they are primarily checking for student learning and not, in normal circumstances, what methods the teacher is using to produce the learning, they may begin to redirect the focus of attention to student learning. Supervisors can further reinforce classroom learning if they model their expectations in the way they ask questions of the students. Questions need to be based on the skills in their lessons, but should be asked in new ways that can not be answered by memorized phrases. For example, supervisors can use questions where the same words are used but rearranged in a way that makes the question new; they can ask students to tell them what they have comprehended from a reading passage; they can ask students to read words with letters that they know but have not seen in their books before; they can pose new math problems for them. The purpose is to determine the extent to which students have internalized new skills and can apply them to new problems. Teachers who see their students questioned this way are likely to begin teaching in a way that ensures their children are prepared for the supervisor's tests, and in the process, students should become more confident. In this way, the best aspects of "exam-driven" systems can be used to make the program work better.

There are life-long implications if school continues to drive the initiative out of children. First, they never become readers because they do not trust their own abilities. Second, they never develop confidence in themselves to solve problems without the help of others. This is not an easy problem to reverse, but gradually over time it can happen if the entire system refocuses on student learning and the objectives of the education system, $(M L E)$.

Assessing the system. The primary purpose of using tests in determining quality is to test how the system works, and only secondarily to see how well individual students perform. ${ }^{16}$ If all children do poorly, one can question whether the test is well constructed, but also one must consider whether the education system might not be at fault. If the scores if any one school, or of the students of any one teacher are poor, there may be indications that something in the management of the school or the training of the teacher requires attention. Knowing where these weak points are helps implementers of programs allocate resources more effectively in remedial training, more focused supervision, or other kinds of improvements. In the end, these assessments provide a cost-effective and reliable way of addressing quality concerns.

The kinds of tests used as quality indicators are important. For example, individual teacher-made tests which appear to be the normal kinds of tests used in Afghan schools have little value in assessing quality. They tend to be arbitrary and variable in the ease or difficulty with which students can complete them. They do not allow for cross-classroom, cross-school or even cross-program comparisons, and because of their arbitrariness they cannot be used to measure changes that occur over time.

School systems in other parts of the world are beginning to realize that without these kinds of measures it is impossible to know where and when to improve the quality of programs. One reason it has taken so long to come to this realization is that "experts" have made many assumptions about what constitutes quality inputs in, for example, teacher training, curriculum materials, etc., and have not bothered to

16 Teachers tend to see instruction as something provided universally to all children of a class, and miss altogether that some children need more exposure to a lesson than others to learn the same thing. If the supervisor tests a few children randomly and finds some are weak, it may be an appropriate time to talk with the teachers about how the skills of the weaker child might be improved. 
check whether these assumptions are true. When teacher training programs fail, they assume it is the teacher's fault or that the training is not yet ideal, and put money into more training. Training and other inputs into an education system are instruments for producing learning outcomes, and should not be considered outcomes in themselves. As instruments, like any other component, they need to be tested in relation to learning before it becomes clear how ideal they really are.

Implementing assessment programs provides a good training ground for staff that is often overlooked. In one Afghan project that collects cross-system achievement data, project staff should be running short seminars for supervisors on the implications of collected data. Their data show, for example, one school where half the children fail, and another where few fail. These real-life situations make an effective learning environment for staff who may be caught up in mechanical ways of performing their roles without looking at the ultimate outcomes of their efforts.

- Capacity to reflect. Assessments are not useful unless they lead to meaningful change. Mechanisms should be created in any good education program that allow for reflection. The present assessment systems used in the Afghan context, if they exist at all, are largely mechanical data collections, or at best strategic planning sessions with an emphasis on operational aspects of project planning rather than thoughtful analysis of either the qualitative or quantitative aspects of education. Without the capacity, time or the information upon which to reflect, projects tend to run on automatic pilot, reproducing the tired methods and flawed results that have come to be seen as positive, impacts.

Reflection is not just a matter for project assessment but is important throughout the education system, from the teachers on up. When possible, simple mechanisms need to be created where reflection is possible. Above, we described an activity (elaborated lessons) teachers could do together to make their teaching easier. This kind of activity achieves a useful product and stimulates reflection. All those involved in the education system need to develop more confidence in their own abilities to reflect on and solve their own problems.

The mechanisms for reflection can be simple: regular meetings, analysis of data, observations in classrooms and discussions about what happens there. Two keys to successful reflection are information and a sense of direction.- the aims of an activity.

\section{Relevance of programs}

\section{Issues of relevance}

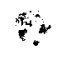

When assistance agencies say their programs aim at "relevance", they appear to mean in programmatic terms that they are "addressing the needs of Afghans". It is not completely clear, however, how Afghan needs have been identified and whether there has been significant input of Afghans in that determination. The question of what is relevant to Afghans appears to be an irritant in the relationship between them and the international assistance community. Important as the issue of relevance may be, it is unlikely that it will be resolved completely until there is an authoritative voice that speaks for the mass of the Afghan population. Certainly in the case of the present authorities, who at the moment claim they are unable to address the issue of a national education system, the problem seems far from being resolved.

The present half-solutions are not entirely satisfactory. Who, for example, should decide the shape of the current education system for Afghans? Should it encompass the old pre-war curriculum goals and objectives, a politicized war curriculum, a curriculum determined by non-Afghans however well intentioned, the adaptations of other nations' curricula, or the determinations of an official government body of Afghans if the results do not match the aspirations of most of the Afghan people? In this context of uncertainty, the only practical strategies may be to work toward the best possible quality in existing programs, the development of 
stop-gap measures to solve the most egregious problems, and frequent reviews of local opinion to determine if there are any major needs that shottld be, but are not now, being met.

While the issue of relevance in the short-run may be addressed with stop-gap measures, in the long-run when stability returns to Afghanistan, the question of setting up a national system should top the education agenda. The anxiety of some that this system might produce too narrow a mandate argues in favor of keeping other models alive to act as alternatives if needed.

Relevance has several implications for the current situation. Who has the authority to speak for the Afghan people and how can the needs of the people be heard and incorporated into curriculum materials? At least two surveys are reported - one is the BBC REACH Needs Assessment, and the other a GTZ/BEFARe survey that attempted to collect local opinion on education needs as a basis for developing relevant education programming. The results of these surveys should be examined to determine what they can contribute to the discussion on relevance. They are likely to raise issues about whose voice should be heard in establishing education programs. Should outsiders be entrusted with decisions about what learning leads to an improvement in the overall quality of village life? Should village people who may not have had a broad enough experience to know the full possibilities of education be the ones who determine curriculum or programming content for the entire population? Can the country - or in the meantime the assistance community - afford a variety of programs suitable for different groups in the society with different needs? Should developers' interests in improving indicators take priority over basic skills with topics such as health, first aid, hygiene, prevention of disease, etc.? Should those who have a political interest in the future of the nation be allowed to promote their various agendas and visions? The first difficult question is who decides what relevance is and for whom it should be designed.

\section{Suggestions of what might be relevant}

Some suggestions are offered here for what might be considered relevant curricula and programs, until such time that an authoritative voice speaks for the Afghan people. The suggestions are based on practical considerations and in some cases the experiences of other countries, but may not be more informed than other views of relevance by outsiders. They include:

- Maintaining options. Existing schooling models, packaged in transportable form as described above, may some day become an' "international" option for communities and private agencies in Afghanistan looking for alternatives to restrictive official programs. At that time they may seem more relevant than they do today.

s.:

- Internationally accepted standards. In the absence of a definitive Afghan voice, it seems important for the Afghan schooling system at a minimum to meet accepted international'standards for what should be included in a basic primary education curriculum. These standards generally include: language, math, science, and social studies, 'with the latter containing such culturally sensitive content that it needs to be developed by local educators. These subjects can be integrated so as not to impose too great a burden on teachers.

- Mother-tongue learning. It is a well-known fact that children learn better when they start their learning in their mother tongue. The emphasis on materials in Pashtu in the refugee schools in Pakistan has disadvantaged Dari-speaking children and should be redressed with more Dari-speaking learning opportunities for them. Language must also be considered in relation to post-primary needs. What second or third languages do children need to continue on to secondary and university levels, or to access employment opportunities?

- Language and national unity. The polarization of Dari and Pashtu-speaking refugee communities in Iran and Pakistan with little opportunity to learn each other's languages is likely to have a lasting effect on social integration and nation-building inside Afghanistan. This is an education issue that has not been fully addressed. 
- $\quad$ Linking with other stages. The fact that most children do not now continue beyond the primary level should not be used âs a reason for shortening the curriculum and foreclosing their options to further education.

- Secondary and tertiary education. While the importance of basic primary education may currently be central to the assistance community, a nation cannot afford to neglect other levels of the education system. Secondary and tertiary stages are both important, if for no other reason than that primary education depends on a cadre of educated professionals. The country may decide to limit the number of highly educated individuals it will support in extended education, but for its own economic and social development it needs trained professionals.

- Maintaining skills. It seems fairly obvious that literacy skills have little value when there are no printed materials available to expand the horizons of the literate. Though the positive relationship between increases in education level and development indicators is an important one, it is not a sufficient justification for undergoing an expensive education process unless there is some benefit in widening the options of the educated. Projects such as ACBAR's "box libraries" can serve as a holding operation until the society develops more widely distributed sources of information. Denying children an education because it is difficult to see the relevance in the settings where they live is also not an option, since it is impossible to know what the future holds for them.

- Cultural fit. Teaching/learning methods can be more easily applied if they are based on patterns similar to those used in conducting social relationships within the society. If student-centered learning does not fit the respect relationships expected between old and young, then teaching methods should be adjusted. This is more than a matter of cultural relevance. It is more costly to change behavior drastically than it is to build on behavior that exists already. Active learning can still go on within this framework, without compromising social values that are also important to learning. The assumption that only certain kinds of learning approaches are effective is questionable, since it is known that children learn by a variety of means.

To establish relevance in education programs requires that needs are communicated to those who have the power to make changes. It is unclear who among Afghans should be carrying out these activities. In the absence of authoritative Afghan voices, piecemeal approaches like those suggested above may be all that is possible. In terms of the curriculum itself, when there is widespread agreement on inadequacies of content, there should be ways Afghans could advocate in favor of actions to close the gaps. ${ }^{17}$ Advocacy strategies on the whole may be insufficiently used by the Afghan community to ensure that their voices are heard. This will be discussed more below.

\section{E. Strengthening capacity within the development community to support quality programs}

This section is written with considerable reservation. A short consultancy is not enough time to assess fully the capacities of organizations involved in assistance to Afghan education. The reason it seems necessary to make some preliminary suggestions is the critical nature of the problem and the fact that several needs are glaringly apparent. The necessity because of time constraints to fočus on deficiencies may over-shadow some good examples that also became apparent in meetings with representatives of the assistance community and through observing programs in the field. It is not the place of this paper, however, to identify strong or weak programs, but rather to suggest how overall assistance efforts might be strengthened.

This section looks at how international assistance agencies, local NGOs, and Afghan government structures might be strengthened to improve their impact in the education sector, and discusses the important question of sustainability.

17 Supplementary materials for example could be used to fill the gap in good science materials, or in the need, expressed by a number of Afghans, for materials to prepare people for peace, reconciliation, and reconstruction. 


\section{Capacity strengthening within the international assistance agencies}

a. International capacity - Needs

An important cause of the current weak state of sector capacities comes from limitations in the assistance environment. Restricted resources, a short-term "emergency" perspective among donors, uncertain future conditions, lack of effective governing structures with which to work, and a desperate and overwhelming need for education services, all contribute to the difficulty of working in the Afghan context. Assistance agencies are called upon to accomplish more with less, and as a consequence issues of quality tend to be assigned a lower priority. The situation would be considerably improved if donors increased the level of funding, allowed more flexibility in their mandates (needs are not all foreseeable), approached the sector more comprehensively (education systems cannot be approached piecemeal), demanded quality programs, and took a longer-term view of both funding support and their expectations of impacts.

Most international agencies (as their staff members readily admit) lack the technical expertise and experience in the education sector to design and develop education programs and delivery systems and, with limited budgets, are unable to hire experts to make up for this deficiency. The result tends to be costly inefficiencies in the delivery of services, and flawed education outcomes. The rapid turnover in international staff contributes to a lack of institutional memory that makes it difficult to build on previous experience.

Assistance agencies generally do not appear to use assessment techniques effectively to measure the results of education programs. Many monitor and supervise their program, but few use these results to improve their programs.

Finally, assistance agencies could make better use of experienced, respected Afghans to advise them in adapting programs effectively to the multiple environments and conditions that exist in Afghan education today.

In brief, the international assistance community needs to:

- advocate for better funding conditions that allow for long-term planning and comprehensive development of education inputs

- develop technical capacity to produce better éducation inputs, programs, and processes

- develop more effective delivery capacity to reach the large number of Afghan communities needing education services

- $\quad$ provide more continuity in its institutional memory and programs so it can build on, rather than duplicate, efforts

- $\quad$ define its short and long-term goals more explicitly

- develop measures to determine the effectiveness of programs

- develop capacity to continuously improve education programs

- develop a closer working relationship with Afghan educators.

\section{b. International capacity - Strategies}

Several strategies to strengthen capacity have been mentioned already in this paper. Where this is the case, they are only briefly mentioned here:

- Technical capacity. Assistance agencies that are involved in the development of instructional inputs (materials, training, etc.) need to ensure that their products meet the highest standards. One way to do this is to hire education specialists with extensive experience in developing countries to supervise the development of the components; or if the components are completed, to assess their quality ånd recommend constructive ways to improve and support them. It goes without saying that new components need to be tested before disseminating broadly. 
- Delivery capacity. The development of more effective delivery capacity has been discussed extensively in the section on "Access". Agencies need to plan strategically for how they can reach the largest number of Afghan communities possible. This planning needs to be short and long-term - i.e., what are the immediate needs for delivery and how might local capacities be developed to expąnd delivery in the future.

- Continuity and history. Assistance agencies need to work more to document their experiences and, especially, their successes. Many projects seem to be reinventing program activities without benefit of their or others' previous experiences. Rapid staff turn-over, though not easily amenable to change, is one of the causes. Documenting lessons learned, successful models, and the details of early project processes (which might provide answers to such important questions as the origins of curriculum objectives) might provide some of the continuity lacking in staff memory.

- Long and short term goals. Assistance agencies need to define their short and long-term goals for their products and programs more explicitly, even when funding is not immediately available to realize the long-term goals. In this way, greater attention will be given to developing inputs and processes with potential for future uses. The agencies that do not take this long-term view waste resources, and though they may not have a project requirement to consider these points, they certainly should have a moral one.

Assessment capacity. Assessment capacity is taken here as a separate technical category, largely because it appears to be the most undeveloped capacity in the assistance community at this time with devastating consequences. The use of routine evaluations and monitoring systems to collect data, while important, does not constitute an assessment capacity without analysis of implications. The objective of education programs is student learning (however that is defined). The objective is not to produce stand-alone training or supervision programs. Training and supervision are only instruments to produce more or better student learning. Assistance agencies need to refocus their efforts back to student learning, which means they must test the effectiveness of training and supervision programs in terms of their impact on student learning, and use this information to improve programs. Although this is a fairly simple process, it may require some experienced experts to develop a systemwide capacity to implement these provisions.

\section{$\therefore$ :}

- Continuous improvement. Education programs with their materials and supports should not be static once developed they must be continuously adjusted to new circumstances and needs. Program components which have been in use for any period of time without adjustment-are almost guaranteed to have problems. Assistance agencies need to develop capacity to continuously improve education programs. This means developing effective information gathering processes, capacity to analyze the information, a forum in which to reflect on the implications, and a process for carrying out the implications. Again, as above, experienced experts may be needed to develop and train staff in a system-wide capacity to implement these provisions.

- Afghan inputs. A group of highly capable senior Afghans exists with experience in curriculum development, testing and implementation (some worked on the Columbia University Project or the UNO project and have degrees and experience from abroad). Their knowledge of the historic context and the current scene in Afghan education can be an invaluable resource for international agencies and donors. Several have links with officials in the current Ministry of Education in Kabul, and are well respected within the Afghan community. 


\section{Strengthening local capacities}

\section{a. Local capacities - Needs}

As long as governing authorities are incapable of effectively delivering education services to Afghan children, a facilitating agent is needed to make the connection between funders and/or developers of programs and local schools. International staff do not have the capacity to execute this role on their own if programs are to be scaled up to meet the need (unless of course assistance agencies decide to expand proportionally). Local organizations can include community development groups, local informal governing groups, regional and national NGOs, and others. An important point, however, is that efficiency in delivery of education programs can only be achieved on a large scale if mechanisms are developed to establish and support programs en masse rather than one at a time. Normally the mechanism is provided by the education structure of a government, but in lieu of such a structure, other agents of delivery need to be found or services will be limited. One assumes these agents of delivery will be replaced eventually by government institutions. However, even in the best of circumstances, future Afghan governments may not have the resources to take on those responsibilities fully, and there may still be room for private initiatives.

Assistance agencies report difficulties in finding enough local partners with the capacity to implement on their own, partly because the "brain-drain" has removed many promising young Afghans from the development scene. The discouraging fact is that any long-term hiatus in the provision of education services at any level (primary, secondary or tertiary) will exacerbate the problem of finding suitable field staff. Finding and supporting local organizations - whether they be community groups or NGOs - to take on a larger implementation role can be one in an arsenal of "flexible delivery systems" available to the assistance community.

On the Afghan side, frustration is expressed with the unwillingness of the international community to strengthen the capacities of local or national NGOs, or to help them survive when funding levels drop during political crises (agencies fund services rather than capacity building). It becomes economically risky for Afghans to involve themselves in assistance activities when funding tends to be short-term and sporadic. For all these reasons, NGOs tend to remain small and concentrate their efforts in limited regional areas, compounding their problems by not being able to take advantage of efficiencies of scale.

\section{b. Local capacities - Strategies $\rightarrow \because$}

Strategies to improve local implementation capabilities lie for the most part in the hands of the international assistance agencies and donors. 'However local organizations can prepare themselves by:

- developing stronger linkages at the comminity level

- demonstrating that they can hire capable staff

- training their staff in local community development drawing on the experience of established NGOs

- $\quad$ using coordinating bodies to build networks and capacities across sectors.

The international agencies who wish to involve local groups further in expanding delivery of their services can build on the following lessons learned in Afghanistan and other countries:

- Select local groups carefully. Selection criteria should include demonstrated successes in community development, geographic experience, language capabilities, size and qualifications of staff, fiscal responsibility and systems for tracking funds, development philosophy, infrastructure such as regional offices, transport, relations with local authorities, etc.

- Define responsibilities clearly. The assistance agencies and local organizations bring distinct skills to education delivery. Local staff bring expertise in areas of community development and locäl implementation. The assistance agencies provide proven education packages and their support programs, and oversight of financial matters if they are the conduit for assistance funds. They can both 
work together to determine the best processes for effectively delivering education packages to communities. Local staff do not need to be education experts, and assistance agencies do not need to be experts in local delivery processes (they do need to be experts in the delivery of education programs inside schools, however).

- Support local organizations with training. If capacities are not sufficient for the task, then assistance agencies need to ensure that local staff receive training in the skills they need to implement specified activities. Afghan organizations should also have a chance to identify their own needs for strengthening, and have some means of accessing the training they need. Though the training capacity of the international assistance agencies may be limited, low cost internships or participation in relevant staff workshops might be offered. Ideal is comprehensive help like that provided by NOVIB in Herat that helped CHA develop the specific skills it needs to carry out its mandate. Perhaps NOVIB could advise the assistance community on how to address the issue of strengthening local organizations.

- Developing capacity for specialized implementation tasks. International agencies with education packages might provide specific training in their use to local organizations wanting to implement the packages on their own as part of comprehensive community development. The "accredited" groups, or their community representatives could be provided the materials and training without cost, with written agreement about the conditions of implementation. If agencies are concerned about the quality of the implementation, they can periodically test student learning and provide short trainings to implementors to correct any problems. Trying this approach first on a small-scale and then on a larger-scale would allow the assistance agencies to experiment with what is virtually a low-cost demand model for education services.

\section{Capacity strengthening within Afghan formal education structures}

\section{a. Formal capacities - Needs}

Some feel it is too early to work with education authorities in Taliban-controlled areas. However, in visits to rural areas near Jalalabad it was clear that many of the formal (ostensibly Taliban) authorities were eager to cooperate in supporting education initiatives. Even if work with education authorities may be limited in these areas, opportunities are plentiful in those non-Takiban controlled areas where a reasonably stable political situation exists (although with few resources to support education). ${ }^{18}$

The need to strengthen local education capacities is there for several reasons:

- the low level of education in the pre-war period in rural areas means that experience is probably limited

- the deterioration of infrastructure during decades-long fostilities requires rebuilding from the start in many areas

- the absence of resources and support for the education sector (which will probabily be the case even when a stable government returns to Afghanistan) - including lack of materials, salaries, and facility construction, rebuilding and repair - means a system virtually at a standstill.

\section{b. Formal capacities - Strategies}

$\therefore$ Several approaches to strengthening the formal system are likely to be productive. The key is practicality of approach, and developing day-to-day capacities to implement programs. It is not appropriate to conduct training that is theoretical and not specifically and observably related to tasks the staff must accomplish. Some needs and approaches include:

- Resources. Lack of resources is a significant problem in all areas of Afghanistan, whether under Taliban control or not, and it is likely to remain a problem for some time to come. Assumingthe presence of a salaried teacher, ${ }^{19}$ the priority need is instructional materials - textbooks being the most important. The second priority is practical training in the use of textbooks and other techniques helpful

18 Unfortunately, it was not possible to visit these areas due to time constraints, and therefore this section is based mainly on observations in Kunar Province.

19 These comments assume that for most of the assistance agencies material assistance to Taliban controlled areas will not be possible until edicts 38

banning girls from schools are rescinded. 
in teaching. The third is enlightened supervision (see above) which drives teacher behavior toward effective instruction. These inputs together can form a minimal education program. The formal system will require this kind of support for many years to come, no matter what the political conditions of the country. At present, providing these material supports will allow the formal system to continue; without them the formal system will fail or continue to produce inferior results. ${ }^{20}$

- Training. Training not tied specifically to outcomes of one kind or another are a luxury under the conditions existing in Afghanistan. There are two kinds of training that may prove effective in building the formal system's capacities. The first is informal modeling of behavior. This kind of training can be effective in any area, Taliban or others, where officials are willing to cooperate in the establishment of schools. NGO staff in such cases need to involve officials as much as possible in the processes they use, keeping their activities transparent and explaining the rationales for what they do. This kind of onthe-job training can be effective in developing and sustaining programs, especially when used as a mechanism for reflection on what are the best approaches.

The second type of training that might prove useful, especially where it is possible to work openly with education staff, is a more structured kind of training. The aim would be to make improvements in staff capacities to manage and supervise education programs. This kind of training would consist of an analysis of the education department's functions conducted collaboratively by the staff and a trainer. The staff would identify its priority functions, describe the processe by which it carries them out, identify opportunities to improve its impacts, and look at how constraints might be removed. In the process, staff would identify the need to improve specific capacities. Follow-on training would address these specific needs. This overall training process could be conducted with the staff of the whole education department or with individuals who have responsibility for managing the department, or with those who have specific functions within the department. A priority concern would be with assessment systems and indicators that allow staff to measure their successes and determine where weaknesses need strengthening.

\section{Building sustainability}

\section{a. Issues of sustainability}

Issues of sustainability are complex in the context of Afghan education. There are several reasons for this. First, many of the usual expectations about sustainability are frustrated. For example, the expectation that once a generation of children go to school, all future generations will go to school has not been realized in Afghanistan. Conditions suggest that the current generation of Afghans will be less well educated than the previous one. Second, skilled staff are usually a prerequisite of sustainability. Disruptions in schooling, and inadequate capacity at the secondary and tertiary levels, makes it difficult to find suffieiently trained staff for schools. Third, resources are needed to sustain an education system. Even when the political situation returns to normal, however, it is unlikely that any government will be able to provide sufficient resources to universalize primary education, much less secondary and tertiary levels. The issue becomes: "Who should support education in the absence of government support?" For many poor communities the answer determines whether they are provided any education services at all.

The assistance community to some extent has aggravated this situation by, on the one hand, providing only short-term emergency funding which makes it difficult to carry out sustained education programming, and, on the other, by insisting upon communities supporting many of the education costs themselves (such as teachers salaries) previously paid by the government. In this "emergency" situation the assistance community is demanding sustainability for programs like home schools that are considered by many to be only interim solutions.

20 Conditions in the formal system at all levels have deteriorated considerably - teachers don't work because they do not receive their salaries, children do not come to school, there are few instructional materials, etc. In Jalalabad, university professors peddle fruit to make ends meet. 
Should the assistance community pay the salaries of teachers or provide free instructional materials? ${ }^{21}$ In a holding operation the answer shoúld probably be yes; for long-term sustainability probably no. Not to pay salaries also sends important messages -e.g., that the role of the teacher is not important enough to warrant payment. For practical purposes it is also difficult to maintain stable institutions without paid positions. This does not obviate the expectation that others (the government or the community) should ultimately take over support for teachers and materials if government structures are regularized, or communities come to a point where they can absorb the costs of an alternative system. Salaries in this time of political instability and the poverty of many returnees seems as much in the nature of "emergency" assistance as anything else.

Some other issues of sustainability include:

- Holding operation or long term capacity building? Make-shift programs may be acceptable as a holding operation, but not as a long-term solution. Building capacity to develop and implement education programs may result in short-term improvements as well as long-term skill development.

- Home-schools. Very much like the BRAC schools in Bangladesh, home-schools are an interim solution with little expectation that sustainability will be achieved. But with small investment and no infrastructure often good benefits can be achieved.

- Community support. Should the community support the costs of edycation? Experience from other countries suggests that the costs of mobilizing communities can often exceed the amount of resources they contribute, and it is difficult to keep people motivated for long periods of time. If significant resources are required, it means that some children will be denied an education because their families cannot afford it.

21 For some reason the sustainability argument has emphasized teacher salaries, when programs are no less dependent when receiving instructional materials and other inputs. In the case of home-schools, decision-makers seem to forget that from a community perspective, a major contribution is being made in providing a free structure. In other words, the burden of a non-functioning government is being placed on the community, which though possibly appropriate in the long-run if the home-schools continue as an alternative, may not be in the short-term if the situation constitutes an emergency. 


\section{SHORT AND LONָG-TERM CONSIDERATIONS}

\section{A. Issues}

The foremost consideration in implementing assistance to the education sector in the short and long-term should be the best use of limited resources. This requires in the short-term that all investments in the sector be reasonably assured of having continuing applicability in the future. Even though it is not possible to predict fully what the future will bring, it is nonetheless possible to recommend options which are likely to have long-term applicability.

From visits to Afghanistan and discussions with members of the assistance agencies working inside Afghanistan, there appears to be considerable scope for activity in the sector at present. The question is not whether anything can be done, but rather how to address the large demand that exists. In certain respects, the flexibility in the current situation creates an opportunity not found elsewhere in the world to identify approaches and models that may cost-effectivaly provide schooling to children well into the future. If these opportunities are built upon, the world may well learn from the Afghan experience how to manage the costs of universalizing primary education.

International experience shows that it takes considerable time to build successful education delivery models. Some well known projects (BRAC, Escuela Nueva, Community Support Project in Balochistan, etc.) that have successfully brought their models to scale have started small and only replicated widely after they have tested their effectiveness. USAID is now funding the development of a community-based model in Morocco that will be tested over several years before it is brought to scale. International experience suggests that the time spent in developing and testing models is well worth the cost in terms of long-term effectiveness. An additional lesson is that careful attention must be given to refining the model itself, and then to questions of installing it in a limited number of places, and then finally in larger numbers of sites. Different issues may be raised when bringing the model to scale than were present in its limited trial, and models can fail if this fact is not taken into consideration. Large-scale replications often need "scripted" processes and documented programs and lose some of the spontaneity of smaller projects.

\section{B. Short-term strategies}

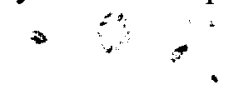

This paper has suggested a number of immediate actions that can be initiated to increase accessible schooling opportunities, improve the quality and relevance of programs, and strengthen capacities to manage and implement education initiatives. These actions, for the most part, are equally appropriate in the various contexts of Afghan education: urban, rural, Taliban and non-Taliban controlled areas, in refugee camps and inside Afghanistan. Their main aims are more effective and efficient education programs and the mechanisms for their delivery. They include:

- $\quad$ simple packaged programs (from existing models) including the minimum required inputs to produce an effective program

- $\quad$ supplementary materials to fill gaps in current programs

- teacher supports

- $\quad$ supervisory systems that "drive" programs toward better learning

- $\quad$ alternative delivery systems: home-schools, community supported schooling, roving teachers, selfinstruction, etc.

- $\quad$ strengthened local NGO capacity to implement programs

- $\quad$ strengthened capacity within the assistance agencies to support the development and testing of appropriate models. 
In the short-term, improvements in these education inputs can have a major impact on children's learning, and the consistency of program offerings in various locations would offer continuity to a mobile population. Their simplicity would allow local staff to manage programs even when not qualified in usual terms. They would allow communities to demand services and have their demands met quickly if they could provide some of the resources to start the program. Opportunities for education services would not depend as heavily on assistance budgets, or alternatively more opportunities could be provided with less.

\section{Long term implications}

One cannot of course predict whether Afghans will continue to want existing education models. There are several reasons, however, to believe that the models may have applicability in the future.

These factors include:

- the lack of government resources to support education (likely to continue)

- the current absence of education infrastructure

- $\quad$ the scattered nature of settlements

- the conservative nature of some populations

- $\quad$ the desire for alternatives to formal education.

It is unimaginable that any local government will be able to provide fully for ducation services for some time to come. For that reason, the development of cost-effective, easily delivered quality schooling models at the present time are likely to be a useful contribution to the country in the long-run.

One of the major issues for the future of the country is the question of how to bring the present modest efforts in education to scale in as cost-effective manner as possible. A number of studies could be usefully performed to provide answers to this question, bút the two most immediate needs are studies of:

- $\quad$ various instructional models to determine their impact on student learning

- various delivery systems to determine which is most cost effective in bringing models to scale.

Even if normal government services are restored need is likely to continue for tested packages to service remote and difficult-to-reach communities, and to service the demand of private institutions or communitybased programs interested in an alternative to the government's program.

In the long run, the goal should be for Afghans to develop theirgwn national education programs. Through involvement in modifying and implementing existing models tơ "make them more efficient and effective for their present and future needs, they can strengthen their skills ${ }^{22}$ for the time when stability-returns to Afghanistan.

The short-term aim, therefore, is to develop and test the efficiency and effectiveness of education models suitable for a variety of Afghan contexts. The long-term aim is to deliver these tested models efficiently and effectively to all children of Afghanistan.

22 A few of the A fghans who used to work in the MOE at the time of the Columbia Project are still in Kabul and Peshawar. These men should be involved in any efforts to improve instructional materials. 


\section{NEXT STEPS}

There are a number of investments in the education sector which are long over-due, and many also that represent a duplication of effort. Both result at least partly from a lack of expertise as well as coordination among donors. To some degree, each assistance agency reinvents the process of providing education services, and because there has been so much concern with delivery and access, the importance of quality and relevance and the long-term capacity to support programs has largely been

neglected. By refocusing on these issues, and sharing the costs of needed developments, the assistance community can improve the chances that Afghans eventually meet their short and long-term education needs.

This paper has aimed at stimulating discussion about how assistance to Afghan education might be strengthened. It has not been the intent to identify a hard and fast set of recommendations that one or more agencies would be required to implement. Rather it is more useful for assistance agencies to work out a common strategy for implementing them. Some of the recommendations are suitable for small individualized efforts (e.g. supplementary materials boxes), while others cannot stand alone and require a more concerted and coordinated effort (e.g. curriculum, training, supervision, and assessment). A next step in this effort should be a general planning effort to determine what agencies would take responsibility for, and which donors would fund the essential actions.

What has also emerged is a pressing need for a forum in which the assistance community could:

- $\quad$ share information, experiences, lessons learned, and databases

- $\quad$ share skills, expertise and technical consultancies

- $\quad$ share models

- $\quad$ avoid duplication of effort in services, model development, geographic region, and targeted groups

- $\quad$ share responsibilities for needs in the sector as a whole

- $\quad$ reflect jointly on their activities and impacts.

One way to address these needs is through a strengthening of coordinating capacities. At present, a variety of mechanisms for coordination are being expłored,; making it difficult for this report to make concrete recommendations on how this might best be achieved. It seems also needed and appropriate to develop a forum for professional development, where those who work in the education sector can up-date their knowledge about the sector and exchange the latest information about what is going on in projects.

The proposal suggested here, therefore, is to meet periodically (twice a year) in a symposium retreat (for 2 days), where a keynote speaker would address the participants in a specialty of importance to the education community. The purpose would be to provide the assistance community with the latest information on a particular aspect of education. As part of the expert's responsibilities she/he would be available to provide advice on relevant agencies' activities. At the meetings agencies would be encouraged to display "story boards" of their activities and products so attendees could become informed about the latest activities in Afghan education. Working groups would be held on the second day to hear short presentations on other relevant and timely issues.

In summary, the next steps for the assistance community would be:

- $\quad$ a concerted plan to address the short and long term deficiencies in the education sector, including an assignment of responsibility and an identification of funders

- the establishment or revamping of a body mandated by various stakeholders to coordinate efforts of the assistance community

- a periodic symposium-retreat for the assistance community to up-grade their expertise, and become informed of the latest activities in Afghan education. 


\section{A. Final word}

The crisis in Afghan education may not be so much a problem of the complicated political situation in Afghanistan, but a result of the serious neglect of those aspects of education that promote quality, relevance, and efficient delivery. Even in the current difficult political climate there is considerable room for increasing and improving education opportunities for Afghan children. Though good examples can be found that might be expanded, assistance agencies at present have limited capacity to ensure a quality product or to bring their programs to scale. Now that world attention is focused again on the human rights situation in Afghanistan, it may be an opportune time to improve the education services provided by the assistance community.

Even in the current difficult political climate

\section{there is considerable room for increasing and improving education - opportunities for Afghan children.}




\section{Summary of Technical Issues: Findings and Recommendations}

\section{A. Needs of the Education sector}

An overview of the main assistance agencies (see text and annex 1) gives some interesting indications about the capacities and experiences that exist within the assistance community. Some of the needs that were identified in the current assistance to Afghan education include:

- $\quad$ more systemic approaches to the provision of education services, including a stronger emphasis on achieving outcomes

- $\quad$ more effective, flexible delivery methods and models that can serve the needs of urban and rural children in different regions

- $\quad$ more attention to the long-term sustainability of education programs

- $\quad$ strengthened capacity within the development community to support quality programs

- $\quad$ strengthened capacity within local education structures and assistance agencies to assume eventual responsibility for the education sector.

At a workshop convened on April 30, 1998, representatives of implementing agencies agreed that the objectives of their education initiatives fell under the rubrics of increasing access, improving quality and relevance, and strengthening capacity to develop, implement, and maintain education initiatives. This paper addresses these three objectives — access, quality and capacity - from a technical perspective.

\section{B. Strategies to maximize access to educational opportunities}

Technical questions related to access relate to the following issues:

- how to deliver education services nore efficiently

- how to massify opportunities

- how to reach school children in a variety of contexts.

The report identifies the following strategies that can lead to greater access to education:

\section{Packaged programs}

Packaged programs support an agreed-upon level of learning, are easily transported and managed at a distance, and allow for rapid response to local demand and conditions. Packaged programs can be refined from existing materials by:

- $\quad$ extracting objectives from instructional materials so that each textbook lesson makes clear what competency is being taught

- developing teacher guides to accompany student texts, with lesson plans showing teachers how to teach each unit of work

- $\quad$ structuring lesson plans in the notes or guides around a predetermined set of effective teaching steps to simplify the process of teacher training

- $\quad$ creating sets of test items from which a monitor or supervisor can prepare tests to assess student learning results

- $\quad$ developing sets of forms to register attendance, and to monitor and report results. 


\section{Supplementary materials}

Supplementary materials, that fill gaps in existing educational services, are required because of large classes, different ability and age levels, little independent learning, and because classes 4-6 are difficult to teach in non-formal schools. The types of materials needed to address specific problems include:

- $\quad$ instructional boxes of graded cardboard reading cards for math, reading and science subjects with comprehension questions included

- $\quad$ self-instructional materials based on the grades 4-6 curriculum for older or more advanced students working on their own or as part of a multi-grade class.

\section{Alternative delivery systems}

- Home-based initiatives: found in both urban and rural areas, and in homes and other community buildings. Potential long-term, low cost model for reaching hard-to-involve children.

- Community-based initiatives are a phenomenon of mainly rural areas in Afghanistan, which have an historic lack of accessible schooling for boys and girls. Community-based initiatives often have difficulties finding qualified teachers, which also raises questions of productive community involvement.

- NGO delivery: Local NGOs have been a useful vehicle for delivering education programs in other countries, especially where issues of scale are concerned. They have often proved more culturally sensitive, may be experienced in community development and in the longrun can be more cost-effective.

- Other options: Alternatives used in other countries include Interactive Radio for teaching subjects such as math, science, and foreign languages; self-instruction; roving teachers and classrooms; and mosque schools where "modern" subjects are added.

\section{IV. "Action" research to scale up opportunities}

Experience has shown that scaling up pilot programs often dilutes the quality of the education offered, even when the model has been tested and appears successful on a small scale. It is appropriate to fund an experiment in massification to determine which are the most cost-effective packages and delivery systems to scale up education opportunities.

\section{Strategies to improve the quality of education programs}

There are a number of basic issues concerning the:quality of Afghan education:

- $\quad$ some materials are an obstacle to student learning while others teach children egven when the teachers are weak

- $\quad$ some teacher notes are complicated and written for highly qualified teachers rather than those who teach in many schools

- $\quad$ some materials encourage rote learning by being too difficult and too compressed for the levels of the children training for the most part is vintage, some being imitations of discredited programs in other countries, little of the training addresses the practical needs of teachers

- $\quad$ supervisors focus on teaching behaviors which are often not appropriate ways to help children learn

- little attention is paid to learning outcomes and when it is, the information collected is often not useful in improving program quality

- almost no mechanisms exist to involve teachers, supervisors, program developers, and others in reflecting on what they do. 


\section{Main strategies}

The main strategies to improve the quality of education programs include measures aimed at improving student learning:

- Assessing curriculum models. An expert needs to assess the various instructional models to determine which are most effective in producing student learning. There are major observable differences in quality.

- Improving supervision. Supervisors create an atmosphere of anxiety among teachers and reinforce behaviors that may not be productive. If a supervisor primarily checks student learning, she/he can redirect the focus of the teachers' attention to learning instead of methods.

- $\quad$ Assessing the system. Student learning needs to be continuously assessed to see how the system works. If all students in a class do well it is not necessary to bother the teacher further; if not, find out what is not working. Tests need to be centrally developed.

- Developing the capacity to reflect. Mechanical data collections that do not contribute to improvements are worth very little. Reflection is important throughout the education system. Create the space and mechanisms for reflection.

\section{Other suggestions for improving program quality}

Other suggestions for improving program quality include:

- Developing a focusing mechanism. Develop a booklet of expectations for student learning by grade and subject to focus all inputs.

- Improving teacher training. Tie all training to the production of student learning. To be effective, training should be "practically driven" by what a teacher needs.

- $\quad$ Providing teacher supports. Self-evident teacher notes/guides help minimally qualified teachers produce desired learning results. The guides can model new approaches, and provide practice in higher order teaching skills.

- Developing "model elaborations" of lessons. Some text books for grade one do not provide sufficient practice in basic concepts. Teachers can develop lesson "elaborations" to improve presentation of these concepts.

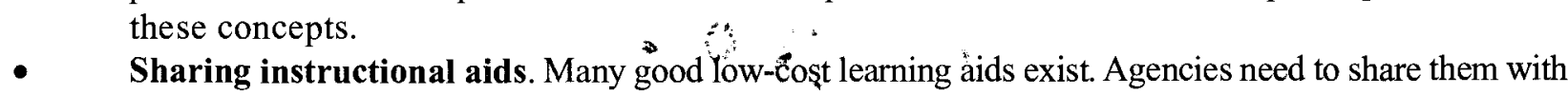
one another.

\section{Increasing the relevance of education programs}

Ultimately, Afghans should decide the relevance of education programs. The comments below reflect the author's personal observations of what might be relevant.

- Maintaining options. Transportable quality packages may some day become the preferred option for communities looking for alternatives to restrictive official programs.

- Maintaining skills. Literacy skills have little value when there are no printed materials available to expand the horizons of the literate. Reading materials need to be developed or translated and activities such as ACBAR's "box libraries" need to be supported and expanded.

- Internationally accepted standards. Afghan education should meet accepted international standards for primary curriculum.

- Mother-tongue learning. Children learn better when they start their learning in their mother tongue.

- $\quad$ Linking with other stages. Primary education should prepare children to move to higher stages. It shouldn't foreclose options.

- Secondary and tertiary education. A nation cannot afford to neglect higher levels of the eđtication system if it is to train professionals.

- Cultural fit. Teaching/learning methods can be more easily and cost-effectively applied if based on patterns of appropriate social relationships within the society. 


\section{Strategies to strengthen capacity within the development community}

The strategies to increase capacity among the assistance agencies include:

- Technical capacity. Developers of education inputs need to hire specialists with extensive experience.

- Delivery capacity. Agencies need to plan strategically for how to address demand for education more effectively.

- Continuity and history. Assistance agencies need to work more to document their experiences.

- Long and short term goals. Agencies need to define short and long-term aims explicitly, even when funding is not available for long-term goals.

- Assessment capacity. Assessment is an undeveloped capacity in the assistance community with important consequences. The objective of education - student learning - is largely ignored.

- Continuous improvement. Education programs and inputs must be continuously adjusted to meet new circumstances and needs.

- Afghan involvement. The assistance community needs more advice from qualified and respected Afghans.

\section{Strengthening local NGOs}

Local NGOs working in the education sector need to:

- develop stronger linkages at the community level

- demonstrate they can hire capable staff

- $\quad$ train their staff members in local community processes and educational methodologies

- $\quad$ build networks and capacities across sectors.

\section{Strengthening international agencies}

The international agencies wishing to expand their programs through local partners need to:

- $\quad$ strengthen their capacity by hiringaqualifiededucationalists

- develop careful selection criteria to ensure the capacities of the NGOs

- $\quad$ clarify responsibilities of each partner (delivery for the NGOs and inputs by the agencies)

- $\quad$ support partner staff with training they need to carry out their assignments

- offer specialized training on packaged programs in order to provide wider dissemination of programs.

\section{Strengthening capacity within Afghan formal education structures}

There is a need to strengthen local education capacities as the infrastructure has deteriorated drastically and there is a general lack of resources. Without certain basic inputs the system will not operate. Assuming the presence of salaried teachers, the priority need for now is instructional materials, mainly textbooks. Providing these materials will allow the formal system to continue; without them, the formal system will fail or continue to produce inferior results.

The second priority is training in the use of textbooks and the third is improvements in teacher supervision. There are two kinds of training that may prove effective in building the formal system's capacities: informal modeling of behavior on the job and more structured training, where officials analyze the education department's functions collaboratively with a trainer, and seek to develop more effective procedures and processes. 


\section{Building sustainability}

Some issues:

- Teacher salaries? Should the assistance community pay teachers' salaries? For effectiveness yes, for .sustainability no.

- Community support? Should communities support the costs of education? Other countries find that costs of mobilizing communities often exceeds the amount they contribute. Also, it is difficult to target poorer communities.

- Holding operation or long-term capacity building? Make-shift programs may be acceptable as a holding operation, but not as a long-term solution. Building capacity to develop and implement education programs can result in short-term improvements and long-term skills.

- Home-schools? Home-schools like the BRAC schools in Bangladesh, are a good interim (and possibly long-term) solution that should not have to build sustainability into their planning. Small cost, often good benefits.

\section{E. Short and long-term aims of the assistance community}

\section{Short-term aims:}

To develop and test efficient, effective education models suitable for a variety of Afghan contexts:

- $\quad$ simple packaged programs

- $\quad$ supplementary materials to fill gaps

- teacher supports

- $\quad$ supervision that drives programs toward better learning

- alternative delivery systems - home-schools, community-supported schooling, roving teachers, selfinstruction, etc.

- $\quad$ strengthened local NGO capacity to implement programs

- $\quad$ strengthened capacity to support the development of models.

\section{Long-term aims:}

To deliver tested models efficiently and effectively:to all children of Afghanistan.

$$
\text { s. }
$$

The next steps the assistance community might want to take in order to achieve these aims are:

- developing a concerted plan to address the short and long-term deficiencies in the education sector, including assignment of responsibility and identification of funders

- $\quad$ strengthening the coordination capacity of the assistance community

- convening periodic symposium-retreats to up-grade educational expertise in the assistance community, and provide the latest information on activities in Afghan education. 


\section{Annex 1 \\ Description of Organizations and Education Projects Assisting the Afghan Education Sector}

The following organizations and/or projects or proposed projects have specific components adressing issues in the education sector.

The information upon which this description is based was the most up-to-date available, but given the rapidly changing nature of assistance to Afghans, there may be changes or omissions the authors are not aware of. This list should therefore not be treated as an exhaustive list of activities in the education sector.

AAEA The Afghan Agriculture and Engineering Agency aims to "improve the quality of education and provide job opportunities" with its 1998 project for the reconstruction of 8 schools in Kabul. This project will benefit 12,000 male and female studènts, who attend the schools in separate shifts, as well as provide jobs for 312 labourers.

ACD The Agricultural Construction Development is an NGO registered with the Ministry of Planning. ACD provides formal education for grades 1-6 and vocational training to disadvantaged children. In its educational activities $\mathrm{ACD}$ follows the Ministry of Education system.

Its funding comes from private sources, as well as from a small UNICEF contribution. Most teachers are semi-volunteers. ACD activities benefit 5,320 children (boys and girls), the majority of whom are in the formal education sections.

ADA Since its inception in 1990, the Afghan Development Association has been working to "implement multisector rehabilitation and development projects which are designed to foster self-reliance and self-sufficiency..."

ADA is implementing an Integrated Education Program (co-funded by NCA and SAVE) in six provinces in Afghanistan, with the objective to "provide primary education to students" in order to "increase the literacy rate among Afghan children"". Besides formal primary education, children receive training in horticulture/agriculture, health education añd environmental awareness. At the end of 1996, ADA had trained and employed 575 teachers who were teaching 17,400 students. In 1997, the number of students in the 108 schools was 23,124 . In the same year, 75 local school committees had been formed.

ADA's construction (construction or repair of school kildings) and higher education program in Pakistan (support to a small number of Afghans living in Pakistản) have come to an end.

AGBAS Ed AG BAS-Ed, the Afghan German Basic Education, is an NGO created with assistance from, and as followup to, GTZ-BEFARe. AG BAS-Ed is an attempt to transfer the experiences of GTZ-BEFARE to Afghanistan itself. The project (turned NGO in 1996) aims "to provide formal and informal education activities and materials for both children and adults", by providing teaching/learning materials, monitoring assistance, evaluation and supervision. The project "wants to make a contribution by meeting the need of Afghans for Basic Education", which shall be achieved "through undertaking activities in the fields of formal and non-formal education..."

Currently, AG BAS-Ed runs the following programs:

- a formal education program (grade I-V; teacher training, supply of text books and materials) for boys and girls: between November 1994 and September 1997, 6,400 students have received education from 133 project trained teachers and supplies have been provided to 13 schools in 4 provinces

- a literacy program in three levels (primer, arithmetic \& reader) for male and female, in Nangahar, Kunazand Khost

- a Mother and Child Health program (training courses)

- an Out of School Children project in 4 provinces, for boys and girls aged 7-14. Presently AG BASEd runs 70 courses for 2,100 boys and girls. 
Aschiana Aschiana aims to "provide children who work in the streets with a vocation and to protect them from risks". It has therefore appealed for funding for a project that will train and feed 2,000 street children and provide entertainment and education in the form of drama and theatre. The aim of the drama and theatre program is "to provide informal education as a means of entertainment to protect the children". The project will include in drama form: basic health education and hygiene, information about the effects of narcotics, the dangers of mines and training related to the rights of the child.

BBC

The world service of the British Broadcasting Corporation is a world-wide radio service, in different languages. For Afghanistan, the BBC is running two special projects: Afghan Education Drama (AED) and Radio Education for Afghan Children (REACH).

The Afghan Education Drama ("New Home, New Life") has been running since 1994. It is an entertainment program, with education and mine awareness messages incorporated into the story lines.

The Radio Education for Afghan Children consists of daily radio programs focusing on numeracy, literacy, Afghan identity, the development of cognitive skills and "understanding the world around us". REACH is a joint effort of the BBC, the International Centre for Humanitarian Reporting (ICHR) and the Academy for Educational Development (AED) and the project will run for three years. Its aim is "to contribute towards producing a generation of Afghan boys and girls with improved communication and analytical skills who are better equipped to take initiatives and make informed decisions affecting their lives; promote a greater awareness and respect for civic/humanitarian values and tolerance; help young Afghans to understand that there is an alternative to war".

BRR BRR, the Bureau for Rural Rehabilitation, has the objective of "understanding the concept of conflict", to analyse conflict and to provide awareness on peace building concepts.

To this end, it is planning to organise trainings for "peace pioneers" and to promote trust among Afghans. It is also hoping to train aid workers in "eliminating the negative impact of aid".

CARE CARE's involvement with education in Afghanistan started with a "Pilot Primary Home-School Project", which was initiated in 1994 and funded by CARE, UNICEF and the Canada Fund. This project opened 52 schools in Paktia province, with 694 students (boys and girls) now completing grade 2. A total of 1,570 students were active in these schools. CARE provided teacher training ( 8 courses since 1995), textbooks and other supplies, using BEFARE books. The communities provided support to these schools in the form of fees (all teacher salaries) and the formation of village education committees.

In late 1997, CARE initiated the Community Organization for Primary Education (COPE) project, which aims to establish 125 community managed schools. This will provide education for approximately 1,700 girls and 3,300 boys. COPE is funded by.DFID and UNOCAL. The COPE project builds on the experiences of the pilot project (in Khost, as well as .Ghazni and Logar), and is based on the same philosophy of community involvement.

To date, CARE community schools provide grade 1 to 5 education for 2,150 children, of which $34 \%$ are girls.

CARITAS The COFAA (Caritas Organizations for Aid to Afghanistan) consortium is led by Catholic Relief Service (CRS). The network is supporting schools in Kabul city.

CCA

The Cooperation Centre for Afghans (CCA) has been working in Afghanistan since 1990. Its objective is to "promote and protect human rights in Afghanistan" and to "provide opportunities for jobless people". Education is a major component in the organization's strategy.

CCA is running a three-year (1997-2000) human rights education program in rural areas, training human rights activists, teachers and media personnel. CCA has also been involved in the construction of school buildings (with EU and NOVIB funding) and at present it supports a technical training school in the North (60 trainees per year). Other activities include literacy classes for street-working children and $\vec{a}$ Traditional Birth Attendance training program in northern Afghanistan, and an income generation cum literacy project for women in Kabul. 
CHA Coordination of Humanitarian Assistance is a Peshawar based Afghan NGO with three main activities in the field of education:

- training for construction supervisors in Herat (191 students)

- administrative/managerial training (in Herat, Farah, Kandahar and Kabul - 3,595 students)

- vocational training in combination with literacy, numeracy and health education (in Herat, Farah, • Kandahar and Kabul - 322 students).

With funding from UNDP, CHA is running a Comprehensive Disabled Afghan Program in Herat and Farah.

COAR CoAR, the Coordination of Afghan Relief, is involved in the construction of school buildings in Wardak and Ghazni provinces, as well as the supply of desks (with funding from the Canada Fund), the payment of teacher salaries and teacher training seminars.

DACAAR DACAAR (Danish Committee for Aid to Afghan Refugees) is one of the major NGOs providing assistance to reconstruction and development of Afghanistan. Its activities in the education sector focus on the rehabilitation of schools and other public buildings.

GTZ-BEFARe The German Agency for Technical Cooperation (Gesellschaft fur Technische Zusammenarbeit -GTZ) is a German federal agency with a development policy mission. Basic Education For Afghan Refugees (BEFARe) is a project of the GTZ in the refugee camps in Pakistan. The main purpose of BEFARe is "to provide and extend basic educational services to children (boys and girls) and adults (male and female)". Since 1995, the project is running two main programs, i.e. formal education and non-formal education, as well as the development of teaching materials and vocational education \& training.

The non-formal education program encompasses mother and child health, adult literacy, out of school children, home schools and vocational education and training. The formal education program provides primary schooling for 62,000 Afghan refugee children in NWFP. This program is implemented by a project by the name of COPE - Community Oriented Primary Education. COPE provides primary education for Afghan refugees throughout NWFP. COPE was established in 1996 and is funded by UNHCR and implemented in cooperation with the Government of Pakistan's Commissionerate for Afghan Refugees (CAR).

Handicap After working for 10 years with Afghan refugees in Quetta, Handicap International relocated its International activities to Afghanistan in 1995. Handicap International's special focus is on disabled people and landmine victims, with the aim of improving "the social, educational and professional integration of disabled".

To this end, Handicap International supports a community-based rehabilitation program around Kandahar and a community-based mine awareness program. The objectives of the latter program are to "reduce the number of accidents in areas affected by mines and to create a 'mine awareness capacity' that will survive after the end of the project". The project consisted of the training of trainers and the setting up of local mine committees. ?."

Handicap International is working under the umbrella of UNOCHA, with support from the EU, UNHCR and Stichting Vluchteling.

IAM The International Assistance Mission has worked in Afghanistan since 1966. It has implemented education programs in Kabul, Mazar-i-Sharif and Herat. In Mazar it is running training programs for blind people as well as skills training programs.

In February 1997, IAM and UNHCR signed an agreement for an IDP schooling project in camps around Herat, benefiting 1,800 children. UNICEF also contributes in the form of teaching materials.

In 1998, IAM is appealing for funding for a series of training courses for physiotherapy, with the aim of training Afghan physiotherapists and to build the capacity of the Afghan health services.

ICC The Islamic Coordination Council coordinates the work of Islamic humanitarian voluntary organizations who work to alleviate the distress of the Afghan, Tajik and Kashmiri refugees. 
In 1998, it has appealed for funding for the establishment of primary schools, in order "to provide basic formal education". These projects in Kabul, Kunar, Paktia and Logar provinces will be implemented by ASC, ISRA, LDI and WAMY. These NGOs have in the last few years established and supported 50 primary and secondary schools, providing education to about 20,000 students (boys and girls) in 13 provinces.

IIRO The International Islamic Relief Organization is an NGO with headquarters in Saudi Arabia. The agency runs a higher education institute in Hayatabad (Islamic Academy for Science and Technology) and supports a number of intermediate and primary schools as well as Quranic centres in Pakistan and Afghanistan.

IKF The Imame Khomaini Foundation Assistance Office has established primary schools in 12 areas in Mazari-Sharif, benefiting ca. 4,000 students. They are also running women's literacy courses and providing scholarships for medical students.

IRC The International Rescue Committee is a US-based refugee organization, which has worked for Afghans since 1980, in NWFP. At present, IRC is implementing a Female Education Program (FEP) Program which aims "to expand access to education for girls residing in the Pakistan-based refugee camps and to improve the quality of education provided in Afghan girls' schools". This program benefits 11,962 students and trained 99 teachers.

IRC also ran a Women's English Language and Computer program (1600 women trained in English, 82 women trained in computing), a Science \& Technology Training Program (closed in June 1997) and a children's program by the name of Kodakistan Education Program (now stopped). IRC's Self-Reliance Program aims at "providing vocational training, employment and income-generation opportunities". With funds from UNHCR, the International Rescue Committee is at present supporting the formal education of 6,100 students in the refugee camps in Pakistan. However, this year IRC is withdrawing from this activity and the responsibility has been taken over by OV.

Since October 1997, IRC has supported community-based education in 3 districts of Paktia province as well as in Kabul. IRC also supports Afghan organizations through its umbrella grant scheme.

ISRA ISRA, the Islamic Relief Agency (a member of ICC), has been working in Pakistan since 1984 and has been running primary schools and madrasas in Afghanistan. Between 1985 and 1992, ISRA supported primary schools in the refugee camps.

KRCS The Kuwait Red Crescent Society has in the past constructed schools for Afghan refugees in Pakistan.

LBI Lajnat Al-Bir Al-Islamiah is based in Jeddah, Saudi Arabia, and is part of the World Assembly of Muslim Youth. It has been running a teacher training institute in Peshawar.

LDI Lajnat Al-D'awa Al-Islamiah is an Islamic charity working for Afghans. In Afghanistan, LDI supports two secondary schools and 8 primary schools ( 5 of which are for girls). In Pakistan, LDF supports a range of institutions, including primary schools, secondary schools, a teacher training institute and Quranic centres, with a total of 7,900 students.

For. 1998, it has appealed for an ICC coordinated project in primary education.

MCC The Mennonite Central Committee supports English language courses for Afghan women in Pakistan.

MEDAIR In the education sector, MEDAIR's goal is "to improve the access to education in Kabul-city for boys and girls, by supporting schools that provide education for girls". The proposed program for 1998 includes a four-month "Informal School Support" project in Kabul. MEDAIR also provides teaching materials.

MMICT Al-Madinah Al Munawarah International Charity Trust has been running orphan care and education services (primary and intermediary) in Chamkani.

NAC The Norwegian Afghanistan Committee has been involved with education projects since 1982, and is committed to support education activities up to 2001. NAC's aim is "to contribute to a better future for 
the Afghan people by securing education for children and young people; to promote female education in Afghanistan".

At present, NAC has the following on-going projects (funded by ODW - Operation Day's Work, a student campaign in Norway):

- primary, secondary and higher education in Ghazni and Badakhshan, for boys and girls; NAC provides teaching materials, salaries, teacher training and construction where needed. This program benefits 6,000 students (500 of whom are girls). In 1998, the program will be considerably expanded in Badakhshan with UNICEF funds and in close cooperation with SCA. NAC's focus will move from school construction to school support.

- partial support for a landmine education project in Kabul, implemented by SC-US, which targets boys and girls.

- a vocational training centre in Ghazni, run by HAFO (Help Afghan Farmers Organization) and which targets returnees, former soldiers and handicapped. The centre is open for males only.

NAC is one of the few NGOs supporting higher education (secondary, high school and tertiary). In 1997, NAC supported 3 girls schools in Peshawar with a total of 1,500 girl students. It is the sole sponsor of Ummahat-Ul-Momineen (Women's University), in Peshawar with 700 students.

NCA Norwegian Church Aid is a non-implementing NGO working mainly through Afghan partner organizations. Its main educational involvement is the support of ADA's Integrated Education Program. ADA is responsible for 108 schools, of which 50 are financially supported by NCA.

In Kabul, NCA gives support to home schools and rehabilitated three schools (in 1997) through two partner organizations. In 1997, NCA and the Taliban authorities formed a Joint Committee on Education, for the support of education to boys and girls in Kabul. NCA and the Norwegian Government made funds available for the rehabilitation of six boys' schools and six girls' schools. Safe transportation for girls to and from schools was also being provided, as were textbooks and other materials. However, the failure of the Taliban authorities to honour the equal access for boys and girls made the Joint Committee defunct.

Other activities include support to primary schools in Gardez (300 students) and Laghman and Nangahar provinces.

NPO/RRAA The Norwegian Project Office/Rural Rehabilitation Association for Afghanistan aims for integrated rural rehabilitation and development and community participation. The objective is to provide opportunities for the return to a normal life. For edycation, this means "to rehabilitate the quality and scope of education processes" through improving education infrastructures in the community.

In 1998, NPO/RRAA is appealing for assistance to construct four high school buildings which will be staffed with assistance from the Logar and Laghman provincial governments. The projects will benefit 3,450 students in three districts. Furthermore, NPO/RRAA'are hoping toconstruct four primary schools in Balkh and Baghlan, benefiting 614 students.

Ockenden OV, the Ockenden Venture, was founded in the UK in 1960 and has been working in Afghanistan for 14 Venture years. The agency is specialised in refugee assistance, and special target groups include widows, disabled and returnees. OV has constructed schools (until 1994) and, with UNHCR funds, operated skills training centres for 2,000 widowed and disabled refugees. This year, it is taking over the UNHCR supported formal education from IRC, providing primary education to 7,000 students.

It is also active inside Afghanistan -e.g. in Mazar where it was engaged in literacy and vocational training (until 1997), and a skills training project in Herat.

OXFAM OXFAM has been running a rural development project in Hazarajat since 1992, working with villagebased organizations. This project includes winter schools (for children up to age 12;3389 students in 1997), women's literacy courses (mostly aged 12-25; 618 students in 1997) and teacher training for both activities. The aim of the project is "to provide basic education (literacy and numeracy) for those poor women, boys and girls, who are excluded from existing provision”.

OXFAM's activities in Northern Afghanistan centre around water supply and construction efforts. The agency has built schools in 3 districts. 
Rädda Rädda Barnen is sponsoring SCF-UK's children's rights project in northern Afghanistan and SC-US's

Barnen landmine education program. Rädda Barnen also supports SAVE's environmental program in Kabul/ Peshawar/Jalabad which has a children's rights awareness raising component to it.

RALSA RALSA has been involved in medical education for over five years. Upto 1997, it trained 2,200 health professionals. At present, the medical education is restricted to male students only.

SAB Solidarite Afghanistan Belgium aims to "upgrade the standard of primary education" through the training of teachers and the provision of literacy courses to adults. A special target group are the refugees.

SAB has worked with Afghan refugees in Pakistan since 1984. Besides being active in the refugee camps, $\mathrm{SAB}$ has programs in 8 provinces of Afghanistan. Between 1992 and 1996, SAB has trained 9,638 male and female teachers and 200 illiterate adults in Pakistan and Afghanistan.

In $1998, \mathrm{SAB}$ are hoping to train 800 primary school teachers and 200 illiterate adults in central Afghanistan and to provide in-service training to 1,720 primary school teachers in the East.

SRCS The Saudi Red Crescent Society supports the Afghan refugees in Pakistan. It has in the past established and supported primary, secondary and intermediary schools, as well as vocational training centres for disabled and orphans and widows in Quetta and Peshawar.

SCA The Swedish Committee for Afghanistan's objectives are to “improve $\$$ he learning conditions of primary schools" and to achieve "primary education of pre-war quality level for children and women in rural Afghanistan". It aims to reach this objective by providing and distributing school materials, supporting primary schools and constructing school buildings.

With funding from the EU and the Swedish government (SIDA), SCA has supported primary schools for boys and girls in the rural areas of Afghanistan since 1984. At present, the program consists of more than 650 schools with 160,000 students (30,000 of them being girls). SCA provides school books and materials, teacher training, salary contributions and, where necessary, repairs to buildings, in order "to provide free schooling" for Afghan children. SCA also provides teacher/headmaster training in order "to improve the quality of teaching and school management in primary schools".

In 1997, SCA organized 81 educasionat and yocational training courses for a total of 2,300 women. The aim of this adult basic education program is "to achieve a literacy rate corresponding to primary school grade 3 among 2,000 illiterate women", in order to "improve the lives of the women and their families". SCA attempts to ensure community participation in its programs, in order "to promote local responsibility for educational affairs". :

$$
\text { (2) }
$$

SCF-UK In the past, Save the Children (SCF-UK) has been working with refugees in Pakistan, as well as in Herat. The Herat education program (school renovation, reconstruction and teacher training) is currently suspended.

In 1998, SCF-UK is hoping to implement a Support to Lower Primary Education project in northern Afghanistan (funded by DFID) and a Children's Rights project (funded by Rädda Barnen). The objective of the primary education project is to address the need for institutional development of the Balkh Department of Education, and the lack of educational opportunities for girls.

Furthermore, SCF-UK is working with local media and the Balkh Department of Education on a "Voice of Education" television project, which aims "to interest the audience in education issues". SCF-UK produces materials for trainings on children's rights and is also engaged in child focused health education through schools.

SC-US Save the Children-USA has education projects in Mazar-i-Sharif (non-formal education and a project for out of school children), Kabul (landmine education project targeting 85,000 children), Quetta (primary education for refugees and women's non-formal education) as well in Haripur refugee villages (non-formal literacy in Dari and Pashtu). 
The objective of all the education projects is "to provide access to relevant, quality education for disadvantaged children and women" in order "to develop knowledge, skills, attitudes and selfesteem, so that individuals can contribute to their own, their family's and the community's well-being and development".

The women's project aims to contribute to women's empowerment. Literacy, numeracy and life skills are taught as means to this end. SC-US is working towards participation gender parity in the primary education project and on constantly improving quality. SC-US implements directly in the refugee camps and partners with committed state institutions within Afghanistan. In the next phase, SC-US will train other Departments of Education and national NGOs to set up and run education projects.

Major donors include UNHCR, UNOPS, PRM, Austcare and the Norwegian government.

SOA

SWABAC SWABAC has appealed for funds for the rehabilitation of the education sector in the south of Afghanistan. With the aim to "reconstruct the education system, to improve and develop the quality of learning for boys and girls", it is hoping to find funding for the reconstruction of 50 primary schools and the provision of textbooks, teaching materials, furniture and teacher incentives.

The project will be implemented by ADA, ABAD, DAFA, SAMSOR, WRO and ARC. The target group of 300,000 students comes from 54 districts and their communities will contribute $20-30 \%$ of the total project costs.

UNO

The Center for Afghanistan Studies at the University of Nebraska at Omaha, in cooperation with ECA, the Education Center for Afghanistan, has been working on the completion of textbooks for secondary education and curriculum development and teacher training "in the areas of home schooling, gender equitable education, adult literacy and mother and child health education." It has also been working on the refinement of the primary education curriculum for Afghanistan.

\section{UNITED NATIONS}

The United Nations agencies in Pakistan/Afghanistan are working on a common program and assistance strategy. To this end, they are trying to apply agreed principles and to improve coordination among the international assistance community.

UNCHS UNCHS-Habitat has been working in northern Afghanistan since 1992, now focusing on urban areas. The agency is running community fora, which can serve as kindergarten, rooms for literacy classes and training centres. UNCHS literacy classes in northern Afghanistan are supervised by the Literacy Department of the Balkh Department of Education.

In 1998, UNCHS-Habitat is planning to produce several thousand textbooks. UNDP is working "to promote non-formal and informal education for girls and boys".

One way of achieving this is through its support for $\mathrm{BBC} \mathrm{REACH} / \mathrm{AED}$ radio programs focusing on numeracy, literacy and understanding of Afghan culture and the world. Other partners in the project include the Radio Partnership of the ICHR and the Academy for Educational Development. The target group consists of "all Afghan children (girls and boys)", from age 8 to 15. 
Furthermore, UNDP and UNOPS are working together on a Comprehensive Disabled Afghans Program (CDAP), set up in 1995? This program targets an estimated 600,000 disabled people and includes an Information, Education and Communication component. At present, the target groups also includes other vulnerable groups, such as widows and orphans.

UNESCO UNESCO aims to promote access and equity in education. UNESCO has adopted a grassroots approach to the reconstruction of education in Afghanistan (GREAT), to integrate education and development efforts. GREAT "envisages to develop literacy, basic education, non-formal education, income generating activities and related skills". Target groups include illiterates, neo-literates and literates among primary school age children, youth and adults of both sexes. In the coming year, a particular target group of a 350,000 dollar project will be the returnees. Various NGOs will implement the program.

Secondly, UNESCO is running a program of Management of Primary Schools Under Stress (MOPSUS). This program aims to provide insights into the causes of lack of resources and to train and support teachers and principals.

Furthermore, UNESCO has developed books on multi-grade teaching, and concept-based books combining 2 grades in the primary areâ. These materials are being used by various NGOs and UN organizations. UNESCO is also assisting in "the development of a policy on education" and training trainers of several Afghan NGOs.

UNHCR UNHCR is responsible for the Afghan refugees in Iran and Pakistan. Under the heading of "education towards repatriation", the organization's brief includes the responsibility for basic education to the refugees. UNHCR supports formal (through BEFARe) and non-formal education (boys, girls and boys\&girls schools; 32,000 people in male literacy classes, 15,000 in female literacy classes and 80,000 women in mother-and-child health courses).

Through its funding of the activities of SC-USA, GTZ and IRC, UNHCR provides education to 78,000 people in the 170 refugee camps in Pakistan. IRC is phasing out and its activities are being taken over by OV. UNHCR is also active inside Afghanistan, with programs aimed at returnees. UNHCR is developing a handbook for teachers of grade 1-6 for all subjects (based on UNO textbooks).

For 1998, UNHCR proposes a pilot project for Educational Activities for Returnees in Kandahar, with UNICEF and UNESCO funding. The arm of this project, which supports 7-9 home-based schools with salary incentives, reconstruction, furniture an̉d textbooks is "to improve access to education for boys and girls and indirectly encourage refugee repatriation". The project also includes support to the Department of Education in Kandahar. Another activity which will start in 1998 is a UNHCR pilot vocational training program, which aims to integrate life skills into the formal and informal educational systems.

$$
\text { . }
$$

UNICEF UNICEF's overall objective in education for its four year programme (1996-1999) is to "support communities to provide quality non-formal or formal basic education, especially for girls, in line with principles of gender equality". UNICEF's approach is to formulate programmes and identify partners for implementation. UNICEF also directly supports education programmes of other organisations, especially programmes that are innovative, or have a potential model function.

Currently UNICEF is supporting the Oxfam winter schools project in the Hazarajat, primary education for displaced children in Herat (with IAM and UNHCR), an informal school project in Kabul (with MEDAIR and UNDP), the CARE community school project (limited to supply of materials). UNICEF also funds the $\mathrm{BBC} / \mathrm{AED}$ project for messages related to education.

For 1998, an emergency education project is being prepared with NAC in Badakhshan, and a rural community education programme in the Eastern Region. Support to schools in Bamyan through Habitat is also foreseen. UNICEF further plans to support activities that will strengthen the overall assistane to the education sector in Afghanistan. 
UNOCHA UNOCHA's objectives relate to "reducing the casualties caused by mines" and other explosive devises through education on the identification and avoidance of risks. In the context of its Mine Action Program for Afghanistan, UNOCHA broadcasts messages and warnings through the media, but it also focuses on community mine awareness activities.

In 1998, the aim is to train 1.1 million Afghans (including IDPs and returnees) on mine awareness. Implementing agencies include ARI, BBC/AED, Handicap International, OMAR and SC-USA.

UNOPS UNOPS started its activities in Afghanistan in 1990, focusing mainly on rehabilitation. Since 1995, it has worked in partnership with SC-USA in non-formal education projects for women. It has also supported women's Quranic classes.

WFP The World Food Program provides food aid to vulnerable women and children in Afghanistan and the refugee camps in Pakistan. It also assists other agencies with food supplies. In the education field, WFP provides teachers incentives, food for kindergartens, and food-for-work incentives for construction of schools and other education activities.

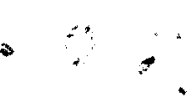


AAEA

ACBAR

ACD .

ADA

AED

AG BAS Ed

ARI

ASC

BBC

BRAC

BRR

CBI

CCA

CDAP

CHA

CoAR

COFAA

COPE

CRS

DACAAR

DAFA

DFID

ECA

EU

FEP

GTZ-BEFARe

HAFO

IAM

ICC

ICHR

IDP

IIRO

IKF

IRC

ISRA

KRCS

LBI

LDI

MCC

MLL

MMICT

MOE

MOPSUS

NAC

NCA

NGO

NPO/RRAA

WFP

ODW

OV

REACH
- Afghan Agricultural \& Engineering Agency

- Agency Coordinating Body for Afghan Relief

- Agricultural Construction Development

- Afghan Development Association

- Afghan Education Drama

- Austrian Relief Committee

- Ansar Relief Institute

-Afghanistan Support Committee

- British Broadcasting Corporation

- Bangladesh Rural Advancement Committee

- Bureau for Rural Rehabilitation

- Community-based Initiatives

- Cooperation Centre for Afghans

- Comprehensive Disabled Afghans Project

- Coordination of Humanitarian Assistance

- Coordination of Afghan Relief

- Caritas Organizations for Aid to Afghanistan

- Community Organization for Primary Education

- Catholic Relief Service

- Danish Committee for Aid to Afghan Refugees

- Demining Agency for Afghanistan

- Department for International Development

- Education Centre for Afghanistan

-European Union

- Female Education Programme

- Gesellschaft fur Technische Zusammenarbeit -

Basic Education For Afghan Refugees

- Help Afghan Farmers Organization

- International Assistance Mission

- Islamic Coordination Council

- International Centre for Humanitarian Reporting

- Internally Displaced Pèrson

- International Islamic Relief Organization

- Imam Khomaini Foundation

- International Rescue Committe

- Islamic Relief Agency

- Kuwait Red Crescent Society

- Lajnat Al-Bir Al-Islamiah

- Lajnat Al-D'awa Al-Islamiah

- Mennonite Central Committee

- Minimum Levels of Learning

- Al-Madinah Al Munawarah International Charity Trust

- Ministry of Education

- Management of Primary Schools Under Stress

- Norwegian Afghanistan Committee

- Norwegian Church Aid

- Non-governmental Organization

- Norwegian Project Office / Rural Rehabilitation Association for Afghanistan

- North West Frontier Province

- Operation Day's Work

- Ockenden Venture

- Radio Education for Afghan Children 


$\begin{array}{ll}\text { SAB } & \text { - Solidarity Afghanistan Belgium } \\ \text { SAVE } & \text { - Society for Afghanistan Volunteer Environmentalists } \\ \text { SRCS } & \text { - Saudi Red Crescent Society } \\ \text { SCA } & \text { - Swedish Committee for Afghanistan } \\ \text { SCF-UK } & \text { - Save the Children } \\ \text { SC-US } & \text { - Save the Children Federation Inc. } \\ \text { SIDA } & \text { - Swedish International Development Agency } \\ \text { SOA } & \text { - Service Office for Afghans } \\ \text { SWABAC } & \text { - Southern \& Western Afghanistan Balochistan Association for Coordination } \\ \text { UNO } & \text { - University of Nebraska at Omaha } \\ \text { UNCHS } & \text { - United Nations Centre for Human Settlements (Habitat) } \\ \text { UNDP } & \text { - United Nations Development Programme } \\ \text { UNESCO } & \text { - United Nations Educational, Scientific and Cultural Organization } \\ \text { UNHCR } & \text { - United Nations High Commissioner for Refugees } \\ \text { UNICEF } & \text { - United Nations Childrens' Fund } \\ \text { UNOCHA } & \text { - United Nations Office for Coordination of Humanitarian Assistance } \\ \text { UNOPS } & \text { - United Nations Operations for Project Services } \\ \text { USAID } & \text { - United States Agency for International Development } \\ \text { WAMY } & \text { - World Assembly of Muslim Youth } \\ \text { WFP } & \text { - World Food Program } \\ \text { WRO } & \text { - Watan Reconstruction Organization }\end{array}$

- Society for Afghanistan Volunteer Environmentalists

- Swedish Committee for Afghanistan

- Save the Children

- Swedish Intemational Developmer

- Service Office for Afghans

- Southern \& Western Afghanistan Balochistan Association for Coordination

- University of Nebraska at Omaha

- United Nations Centre for Human Settlements (Habitat)

- United Nations Development Programme

- United Nations Educational, Scientific and Cultural Organization

United Nations High Commissioner for Refugees

- United Nations Office for Coordination of Humanitarian Assistance

- United Nations Operations for Project Services

- United States Agency for International Development

- World Food Program

- Watan Reconstruction Organization

Photo Credits: Patricia Garcia -

Andrew Wilder

Save the Children $\mathbb{R}$

UNICEF

United Nations Children's Fund (UNICEF)

Afghanistan Country Office

17-B Abdara Road

P.O. Box 1078

University Town Peshawar

N.W.F.P. Pakistan

Ph: 92-91-43669

Fax:92-91-840437

\section{Save the Children ${ }^{\circledR}$ \\ Pakistan Afghanistan \\ Field Office}

P.O. Box 1952

House \# 7A Street 58 F-7/4

Islamabad Pakistan

Tel: $92-51279211-3$

Fax: 92-51 279210
Save the Children ${ }^{\circledR}$

U.S.A. Head Quarters

54 Wilton Road

Westport Connecticut 06881

Tel: 1-203-221-4000

Fax: 1-203-221-3799/4082 
